\title{
Reproductive Experiential Regulation of Cognitive and Emotional Resilience
}

Craig H. Kinsley ${ }^{1}$, Karen Bales², Massimo Bardi ${ }^{3}$, Danielle Stolzenberg ${ }^{2}$

1: Department of Psychology-Neuroscience, University of Richmond, USA;

2: University of California-Davis, USA;

3. Department of Psychology, Randolph-Macon College, Ashland, VA, USA

Running head: Moms, brains and resiliency 


\begin{abstract}
Adaptation virtually defines survival. For mammals, arguably, no other developmental milestone is exemplified by - nor more reliant on - the sudden and dramatic behavioral alterations observed in the maternal female, which rapidly must undergo change in order to express a large suite of proper and effective maternal behaviors. As pregnancy progresses, as well as during lactation, when pup cues are rich and rampant, the female is literally transformed from an organism that actively avoided offspring-related signals, to one highly motivated by those same cues to build nests, be attracted to pups and to retrieve, group, groom, crouch-over, care for, and protect, the young. Ancillary responses such as reference memory, spatial learning, foraging (including predation), and boldness improve in mothers compared to virgins. Such modifications arise early and are persistent, with neural benefits that last well into senescence. Evolutionarily, such enhancements have likely reduced the maternal burdens associated with sheltering and feeding the vulnerable young; collectively, this strengthens the mother's/parent's reproductive fitness and that of the pups in which all this effort is invested. Of the many behaviors that change as a function of pending or concurrent maternity, therefore, what is the role of modifications to resilience, the ability to withstand the numerous, unpredictable, and threatening environmental events that the mother/parent must daily, indeed, multiply daily, face and thwart in order to bring the offspring from pups to fully functioning adults. We explore these questions, and their connections, here in a multi-disciplinary manner focused on the constellation of change that summates to fundamentally alter the female for the rest of her life. Behavior, brain, neurochemistry and genes are fundamentally changed as the substrate for reproduction unfolds and expresses its inherent plasticity.
\end{abstract}




\section{Maternal Brain-Induced Resiliency}

In the current manuscript we will argue for, and present evidence strongly suggesting, that mothers are made, not born. Further, it is apparent that there is a lot of building going on. For the maternal mammal, the construction site includes the central nervous system, which is acted upon by a relentless cascade of pregnancy-induced hormonal stimuli. Such actions

render the sensitive neural substrate both motivated toward, and responsive to, the offspring, whose own stimuli may maintain what the hormones began (Kinsley et al., 1999; Lambert et al., 2005). The new mother experiences a most significant and transformative event during this conversion from virgin to mother, nulliparity to primiparity, self- versus other-directed. Along with the creation of a litter bearing half of her genes, the episode graphically demonstrates the inherent plasticity of the female brain, a neural flexibility that is expressed only following the onset of pregnancy. Given the enormity of the changes occurring, we believe that this period represents a developmental epoch every bit as significant as sexual differentiation and puberty, which precede it. "M" may be "for the many things a mother does," but it is the "M”odifications in her neural substrate that lead to significant augmentations in her survivability, the attention devoted to her pups, and hence, their survival.

\section{$\underline{\text { Nature Gives Moms a "Boost," which Likely Translates into Behavioral Economies }}$}

For any new mother, the adjustment from nulliparous to parous requires a throng of modifications, especially in mammals. For the female rat, provisioning her nest and its new inhabitants takes precedence, where finding and acquiring food or subduing prey is integral to everyone surviving another day; but the process of reproduction begins almost immediately 
after menarche. The obstacles arrayed against successful reproduction, however, are formidable and many. They range from properly functioning physiology; the discovery and acquisition of a suitable mate; actual mating; a healthy, event-free pregnancy; development of the embryos/fetuses; full and effective parturition, itself freighted with multiple dangers, and the healthy delivery of the infants. Then, should the offspring be born successfully, the mother's work only just begins. It appears, though, based on a raft of converging data, that evolution has bestowed on the mother some incremental advantages that help her adapt to the short-term but intractable obstacles arrayed before her.

For example, in order to manage a likely vulnerability-laden nest (it is a nest, after all, not a fortress) and a group of insistent young, the new mother forges a Faustian bargain, a balance of costs and benefits: does she stay or does she go? Hazards/predators await both her young and her should she leave the relative safety of the nest and her helpless offspring to forage for food and resources. Equally hazardous, she could remain ensconced in her nest, safe, protected, but guaranteed a slow, mutual, and costly fate for pup and mother alike. Enter maternal nervous system adaptation -- and the many accompanying behavioral solutions which ensue, leading to greater survivability. Her decision is aided by positive modifications to behavioral economies, that is, tiny savings in time, effort, resources, etc., that accrue and contribute to the survival of mother and young. Maternal plasticity, therefore, is insurance against genetic oblivion.

Most researchers have looked at maternal behavior per se, as a unidirectional phenomenon, ignoring the reverse events. That is, the mother certainly cares for young, and the benefits accrue to offspring alone through the labors of the mother. We, however, have taken a different tack as we examine the maternal-infant interaction. We realized that the 
offspring could be viewed as a form of enriched environment, providing the mother's brain with a flood of rich stimuli. For example, beginning with the pregnancy, the levels and length of exposure to the powerful hormonal events are themselves capable of significant anatomical alteration. Elevated levels of estradiol, progesterone, prolactin, relaxin, and other hormones are released for extended periods, acting on a malleable brain and nervous system very sensitive to them, an event that recalls a heavy rain falling on a fertile plain. Add to this mix a complicated cascade of neuropeptide events including oxytocin, neuropeptide-Y, substance-P, cholecystokinin, galanin, etc. (Josefsson et al., 2010), likewise indicate a volatile neurochemical landscape absorbing and responding to these ligand signals. Thus, many of the neuroanatomical changes reported during pregnancy (Keyser et al, 2001; Kinsley et al., 2006, etc.) are assuredly due to the endocrine and related events of pregnancy literally making their mark.

The many hormonal and other actions that accompany pregnancy exert multi-level changes and thrust plasticity upon the female’s brain, which in turn, enhances learning and memory. It is a complicated story, however, that begins with the normal plastic changes that mark the female's estrus cycle, and which presage the even greater modifications that occur with pregnancy and beyond. A brief description of these effects are illustrative of the greater ones to follow. For example, Berry et al. (1997) examined learning related to hormonal status in the female rat. These subjects' spatial navigation was assessed at particular points in the estrus cycle that corresponded to low (viz., during estrus) and high (proestrus) circulating estrogen levels. Following water-maze training, the rats were taught the location of an escape platform in the maze in a single session of eight training trials. Estrus and proestrus rats were indistinguishable on all behavioral measures, irrespective of their hormonal status during the 
task. The authors conclude that rapid learning and retention for spatial information over a relatively short interval may be reserved independent of the morphological alterations in hippocampal dendritic spine density that normally occur over the span of the estrus cycle. There have been reports of estrus-cycle/hormonal effects on other, more molecular/functional aspects of learning. For instance, Woolley et al. (1990) recorded electrophysiological alterations in neuronal activities that paralleled stage of the estrus cycle, with proestrus having the greatest degree of change. Warren et al. (1995) reported that long term potentiation (LTP), a purported mediator of learning and memory (Kandel, 1991), varied across the estrous cycle in rats. The greatest degree of potentiation occurred during the afternoon of proestrus, also a time that others had reported as having the highest degree of dendritic spine and synapse number (McEwen \& Woolley, 1994; Woolley et al., 1990; Woolley \& McEwen, 1992, 1993). Warren et al. suggest that "proestrus may be a period of heightened structural modifiability which may facilitate the formation of new connections in response to high frequency stimulation...” (p. 29). Therefore, the reported neuroanatomical alterations that accompany the estrous cycle may facilitate LTP, which may be reflected in enhancements of cognition. The latter includes maze performance and spatial ability (Warren \& Juraska, 1997). And as discussed later, molecular actions of oxytocin on neuronal dynamics (Tomizawa et al., 2003), particularly in hippocampus, may demonstrate a complementary interface between structural and functional aspects of this neuropeptide’s evolutionary relevance.

Also, the hippocampus reflects the demands placed upon it. That is, if an animal (male or female) must range a long distance for mates or food, hippocampal volume is greater than one whose territory is smaller (Gaulin, 1995; Gaulin \& Fitzgerald, 1986; Jacobs et al., 1990). 
We have argued that a newly-parturient mother must adjust her behaviors in order to effectively care for pups (Kinsley et al., 1999) - adjustments that could include ranging farther and wider for food, water and other provisions. We and others have since reported that hippocampal neuronal modifications that suggest long-lasting and pervasive effects of gonadal steroid exposure during pregnancy, coupled with pup exposure, and facilitation of the acquisition of spatial tasks, occur in parous animals (Bodensteiner et al., 2005; Pawluski \& Galea, 2006; Gatewood et al. 2005; Kinsley et al., 1999; Love et al., 2005; Lambert et al., 2005).

\section{The Offspring Likely Play a Role in their Own Survival}

Complementing and likely eclipsing the neurochemical actions of pregnancy, however, is the deluge of offspring-induced sensory feedback to which the new mother is exposed. The sights, sounds, odors, tastes, tactile and suckling stimulation, the rich milieu of maternity, that is feeding back onto a hormone-sensitized brain is likely enormous. Alone or interacting with the above neurochemical events (Kinsley et al., 1999) would represent a tremendous sensory load stimulating a variety of neuroplastic activities (and may underlie the stimulation of maternal behaviors in foster parents). Some of these stimuli directly benefit the offspring (e.g., maternal behavior), others may aid the mother (e.g., enhanced cognition, decreased stress responsiveness). A fascinating example is work by Bridges and colleagues (1996). It appears that late-term fetuses can stimulate their mothers' brains to produce maternal behavior by means of the release of placental lactogens, thereby redundantly establishing a greater likelihood of adequate maternal care: the mother receives cues from her own (endocrine and other) system as well as from the pups'. In an important way, therefore, 
perhaps the pups play a significant role in their own survival: they help both to maintain their mother's motivation toward them, and to provide her with a sensory boost to her own cognition, thereby enabling her to more efficiently provision them. It is an intriguing idea supported by the data (Kinsley et al., 1999).

\section{Predation, a Hallmark of Survival, Improves with Maternity}

What might some of these ancillary behaviors look like? Positive modifications to spatial memory and predation would be expected to benefit the mother (Gatewood et al., 2005; Kinsley et al., 1999; Love et al., 2006), contributing to her foraging more efficiently and then returning to her nest and defenseless pups more quickly. As discussed above, reproductive experience modifies cognition, including enhancements of spatial ability; reductions in fear and anxiety; and lifelong improvements in learning. Does it extend to related behaviors? We have recently extended our observations to predation. Given the importance of hunting to an animal's survival - even one as domesticated as the laboratory rat - we examined how this basic behavior might be affected. We have observed striking differences between mothers and nullipara in predation and its sensory regulation (Kinsley et al., 2014). Mothers far-and-away outperform non-mothers. Lactating and mid/late pregnant (M-LP) rats out-performed nullipara - despite the fact that M-LP are nearly 25\%-33\% heavier. This motor paradox resembles human changes involving pregnancy modifications of vertebrae, a compensation for bipedal obstetric fetal load (Whitcome et al., 2007). In other words, the female may adapt to the pregnancy weight-gain, culminating in significant improvements to motor function. Further, predation under 0-lux conditions, however, eliminated the differences, by increasing predation latencies in the moms, and decreasing 
them in the nullipara. This sensory manipulation suggests improvements to vision in the former group, which the 0-lux testing eliminates, whereas the effects in the latter exploit the natural hunting tendencies of this nocturnal animal. Offspring place enormous demands on mothers/parents not required of nullipara. Hence, enhanced predation (via possible visual modifications) is an important adaptation, illustrating the economics of survival. The aforementioned improvements, predation foremost, equip the mother to care more efficiently for her significant metabolic and genetic investment. They add to the resilience with which the female must face her unforgiving environment.

\section{Additional Evidence for Behavioral Resilience and Efficiency}

Other recent work addresses complementary features of the maternal plasticity. Love et al. (2006) reported that, under competitive conditions where weight-matched nullipara were pitted against primipara and multipara for a learned food reward, the multiparous females (60\%) significantly out-performed both the primipara (33\%) and nullipara (7\%) in that they achieved the food reward more quicklyw. These data suggested the possibility of an advantage that may accrue to parous females as they compete, post lactation, for mates, territory, etc. We liken this effect to a bettor choosing between a known quantity (the parous animals) versus an unknown one: the nulliparous female may be fertile and fecund, with the potential to mate and produce viable young, but she has not demonstrated her capacity. Whereas, in contrast, the parous animal is a known quantity, with a track record. Would males show a preference?

We have recently examined this question (Anderson and Kinsley, unpublished). Virgin or stud males were given the opportunity to interact with odors from nulliparous or 
parous females. Stud males displayed a significant preference (defined as time spent in the vicinity) for parous females, whereas virgin males displayed a trend in the direction of parous females. These data, though preliminary, suggest that reproductive experience may regulate sexual attraction in a way that confers an advantage to parous animals. Such effects would add to the growing body of data that demonstrate extra-reproduction effects that extend into vastly different arenas of the female's life, but which may promote additional facets of reproductive success. Notwithstanding, it is apparent that the experiences associated with reproduction fundamentally alter the female. And not just mammals, either: we have data in a variety of wolf spider (Hogna aspersa) that females carrying young are more likely to turn and confront a predatory wasp, compared to non-parental females, who prefer to seek refuge in a covered spot (a hide box) placed in the test arena (Choi \& Kinsley, unpublished). Maternally-enhanced aggressiveness and hunting skill, together with a variety of germane neuroplastic changes, may be characteristic of "mothers" across a number of species faced with the prospect of reproduction in an unforgiving environment. For instance, Beach, in an interesting parity effect itself, reported that female mosquitoes transform from passive creatures to the tiny annoyance we endure due to hormone induced modifications necessary to provide a blood meal for their developing offspring (Beach, 1979). Furthermore, the preceding gene expression events may parallel what we and others have found regarding the cognitive and other changes that accompany parity. For instance, Toth et al. (2007) examined social wasps, reporting that exposure to young or reproduction itself leads to the expression of a wide number of genes, with telling effects on a cluster of insulin related peptides, the same product of which is reported to modify hippocampal activity in positive ways (Chen et al., 2011). The latter are themselves implicated in hippocampal function, synaptogenesis, and 
memory in mammals (rats; Wan et al., 1997), as well as neuroprotection (Dore' et al., 1997) of the sort observed above (Gatewood et al., 2005). And these genes, particularly related to the insulin family, interestingly, overlap with some that we have identified as important for maternal behavior (Kinsley et al., 2008; Kinsley, Franssen \& Meyer, 2012). Life is life, reproduction, reproduction, regardless of where one resides on the phylogenetic scale.

Modifications in aggressive behaviors and resilience markers would be predicted to provide the parous female with an additional bulwark against the perils in the environment that confront her and her offspring. Perhaps, therefore, parity changes are the rule for females from any species confronted with the innumerable challenges of rearing young, invertebrates to vertebrates. Section II examines some of the underlying molecular neurobiology of the parental animal, which may contribute to the vast store of behavioral change that is beginning to take shape.

\section{What constitutes motherhood?}

For most altricial (immature) mammals, survival depends on the caregiving behaviors of the mother. Mothers provide warmth, protection, and food, calm and soothe their infants, and play a critical role in their social and cognitive development (Esposito et al., 2013; Hackman et al., 2010; Numan, 2003). The transition to motherhood is comprised of a sensitive period during which mother-infant interactions facilitate subsequent mothering behaviors. For example, increased contact with infants during the early postpartum period is 
associated with sensitive mothering, better breastfeeding outcomes, and increased attachment (Bystrova et al., 2009; Erlandsson et al., 2007; Gross et al., 2011; Mehler et al., 2011). These experiences, particularly in the context of peripartum hormonal stimulation, can increase the mother's sensitivity to infants and infant-related cues. Human mothers, for example, are better able to discriminate infant odors compared to non-mothers (Fleming et al., 1993; Fleming et al., 1997; Nishitani et al., 2014). Further, the sensitivity of mothers to infant cues suggests biological changes: fMRI studies demonstrate that mothers have increased neural responses to infant stimuli when compared with non-mothers (Kim et al., 2010; Nishitani et al., 2014; Seifritz et al., 2003).

Rodent models work well for investigating the neural mechanisms that underlie maternal responsiveness, because female rats and mice are also attracted to pup odors and related cues (Bauer, 1983; Fleming et al., 1989; Kinsley and Bridges, 1990). Similarly, the transition from virginity/nulliparity to motherhood involves hormonal and/or experiential mechanisms that tune sensory systems for perception of pup cues [for review see (Banerjee and Liu, 2013)] and enhance caregiving behaviors even under challenging conditions (Agrati et al., 2011; Bridges et al., 1972; Gandelman, 1973; Stern and Mackinnon, 1976; Stolzenberg, 2011; Stolzenberg et al., 2012, 2014). Finally, note that the maternal transition results in permanent changes in maternal responding. For example, following initial mother-pup interactions, maternal responding is sustained for up to several months in rodents, which suggests a powerful regulating effect (Bridges, 1975; Bridges, 1977; Bridges, 1978; Fleming et al., 1999; Orpen and Fleming, 1987; Orpen et al., 1987; Scanlan et al., 2006; Stolzenberg et al., 2014). 


\section{What Are Some Of The Molecular Consequences Of Becoming A Mother?}

The onset of mothering behaviors, as discussed above, is typically accompanied by exposure to fluctuating hormones during pregnancy, birth, and lactation. Specifically, the hormonal changes that accompany birth (rising estradiol, placental lactogens, prolactin, oxytocin, and progesterone withdrawal) synchronize the onset of caregiving behaviors with the delivery of offspring (Numan, 2003). A substantial body of work supports the idea that interaction with infants in the context of these hormonal changes supports the long-term behavioral responses toward them, described above, by increasing the activity of neural circuits that regulate approach responses, while dampening the activity of neural circuits that inhibit the maternal state (Numan, 2006). The mechanisms through which hormonal stimulation initiates maternal care likely involve an alteration of the medial preoptic area (mPOA). Initial mother-pup interactions in the context of these hormonal changes activate immediate early genes within mPOA neurons (Del Cerro et al., 1995; Jin et al., 2005; Kuroda et al., 2007; Kuroda et al., 2008; Numan and Numan, 1994, 1995; Numan et al., 1998; PerezLaso et al., 2011; Tsuneoka et al., 2013; Wu et al., 2014). Microarray studies have identified several genes that may lie downstream of immediate early gene activation (Akbari et al., 2013; Gammie et al., 2005; Kuroda et al., 2007). These gene expression changes may alter the phenotype of mPOA neurons, modifying the type of stimuli a particular neuron responds to as well as the type of response elicited (Sheng and Greenberg, 1990). Thus, the combination of hormonal stimulation and pup inputs might modify mPOA neurons such that they are responsive to pup inputs even after the hormonal events of birth wane, like a pump that has been primed. In support of this idea, upon re-exposure, increases in neuronal activation (as measured by c-fos) suggest that phenotype of mPOA neurons has been altered 
so that they permanently show a heightened response to infant stimuli (Fleming and Korsmit, 1996; Fleming and Walsh, 1994). Importantly, the experience of interacting with infants even in the absence of hormonal stimulation can produce similar alterations in mPOA neurons. Thus, hormonal and experiential factors may affect maternal behavior by activating similar mechanisms within the mPOA (Stolzenberg and Numan, 2011).

A variety of research programs has begun to explore the overlap in cellular markers associated with rodent parental behavior in the presence and absence of gestational hormones (Canavan et al., 2011; Kuroda et al., 2007; Wu et al., 2014). From a mechanistic perspective, steroid hormones were traditionally described as producing slow acting, but long lasting effects on gene transcription as ligand-bound transcription factors (Beato and Klug, 2000). Several findings, however, seem to contradict this simple explanation. Thus, mechanisms of steroid hormone action have been expanded to include non-classical effects, which explain how steroid hormones may regulate the expression of genes that do not contain consensus steroid response elements. For example, steroid hormones have been found to directly interact with proteins that control transcription at non-steroid responsive DNA sequences, as well as directly activate certain enzymes (map kinase [MAPK], extracellular regulated kinase [ERK], cyclic-AMP response-element binding protein [CREB]), which ultimately modify gene expression through the activation or repression of transcription factors (Abraham et al., 2004; Beato and Klug, 2000; Bishop and Stormshak, 2008; Bjornstrom and Sjoberg, 2005; Foradori et al., 2008; Kelly and Levin, 2001; Mhyre and Dorsa, 2006; Toran-Allerand, 2004; Vasudevan and Pfaff, 2007, 2008).

With respect to the onset of maternal behavior, it is likely that in addition to classical mechanisms of estradiol action, non-classical effects of estradiol are also involved 
(Stolzenberg, 2009; Numan, 1977). Given that estradiol plays such a ubiquitous molecular role, it is perhaps not surprising that in the absence of estradiol, experience-induced onset of mothering described above may be able to activate similar signaling pathways as estradiol [see (Stolzenberg and Numan, 2011) for review]. In support of this idea, in C57 mice, experience with pups induces behavioral and molecular changes that are associated with newly parturient females. Similar to early postpartum mice, pup-experienced virgin mice are significantly more responsive to pups on a novel T-maze than inexperienced virgins

(Stolzenberg, 2011). Further, some of the gene expression changes that have been reported in postpartum rodents (Champagne et al., 2003; Gammie et al., 2005; Peña et al., 2013) are also affected by maternal experience in virgin mice (Stolzenberg et al., 2012). Hence, the many stimuli associated with young - the sights, smells, sounds, tactile and suckling stimuli - may play a supra-hormonal role in the regulation of parental behavior.

\section{What molecular mechanisms maintain the maternal state?}

Whereas the surge in estradiol at birth is fleeting, the maternal state is permanent. Once mothering behaviors are initiated, these behaviors are sustained until the offspring are weaned - and beyond. How does this relatively short-lived signal produce such long-lasting effects on behavior? The answer to this question may be related to the ability of estradiol to remodel chromatin (Mann et al., 2011). Both classical and non-classical mechanisms of estradiol action may be mediated, at least in part, by chromatin remodeling. Chromatin remodeling involves covalent modifications that produce structural changes to the chromatin: DNA and associated histone proteins. Classical mechanisms involve the dimerization of estrogen receptors (alpha and beta) in response to ligand binding, translocation to the nucleus, 
and direct interaction with DNA sequences in estrogen responsive elements in the regulatory regions of target genes. This process involves recruitment of co-factor complexes, which scaffold estrogen receptors to basal transcription machinery and/or chromatin components, typically switching genes from a basal to an activated state (Nilsson et al., 2001). Importantly, these cofactor complexes can enhance gene expression by directly modifying histone proteins (Mann et al., 2011). Non-classical mechanisms involve ligand-bound estrogen receptors directly or indirectly interacting with histone modifying enzymes, which ultimately switches on/off chromatin at non-steroid responsive DNA sites. Thus, both classical and non-classical mechanisms of estrogen signaling likely involve chromatin remodeling.

Histone acetylation is one well-characterized mechanism by which estradiol remodels chromatin (Mann et al., 2011). Ligand-bound estrogen receptors (both alpha and beta) recruit the co-activator CREB binding protein (CBP). CBP is involved in catalyzing the transfer of acetyl groups to lysine residues of histone protein tails, which neutralizes the positively charged histones and weakens their association with negatively charged DNA (Kalkhoven, 2004). Thus, histone acetylation can physically open up the chromatin, allowing the transcription machinery better access to gene regulatory regions. Owing to this enzymatic activity, CBP is considered a histone acetyltransferase (HAT). Note that the HAT activities of CBP can be reversed by histone deacetylases (HDACs). Shifts in the activity of HATs and HDACs can therefore affect gene expression. Estradiol administration alone can increase histone acetylation within the hypothalamus (Gagnidze et al., 2013). Intriguingly, given oxytocin’s (OT) plentiful roles in the reproductive drama, estrogen-mediated transcription of the OT gene is driven by CBP recruitment and histone acetylation to the OT gene promoter 
(Sharma et al., 2012). Furthermore, administration of HDAC inhibitor drugs potentiates the transcriptional effects of estrogen receptor (both alpha and beta) stimulation (Duong et al., 2006). To our knowledge, the extent to which these estradiol-induced chromatin changes mediate the onset of maternal behavior at birth is presently unknown, but the possibility seems likely. Only additional work will tell for certain.

If initial mother-pup interactions are consolidated on the backdrop of estradiolinduced chromatin changes, a relevant question is whether experience with pups alone, which can also lead to long-term changes in maternal care might also recruit epigenetic mechanisms. Given that recruitment of the co-activator and HAT, CBP, is a mechanism through which estradiol enhances histone acetylation, it is possible that in the absence of estradiol stimulation, other neurotransmitters my recruit HATs to initiate similar plastic cellular changes. Thus, one possibility is that in the absence of pregnancy hormones, repeated sensory inputs from pups ultimately stimulate the same molecular pathways. CBP-mediated histone acetylation is a logical candidate mechanism because CBP can be turned on by hormonal factors (as described above), as well as experiential factors (neural activity during motherinfant interaction), and permanently affects the regulation of gene expression in mPOA neurons by remodeling chromatin (Cortes-Mendoza et al., 2013; Edwards, 2000; Riccio, 2010). In support of these ideas, Stolzenberg and colleagues have recently found that repeated experience with pups increases maternal responding and CBP gene expression in the mPOA (Stolzenberg et al., 2012, 2014). Further, sub-threshold mother-infant experiences, which do not result in sustained maternal responding, are potentiated by administration of an HDAC inhibitor. Increased expression of estrogen receptor beta and oxytocin genes in the 
mPOA that are associated with the consolidation of maternal experience are also potentiated by administration of an HDAC inhibitor and seem to be driven by recruitment of CBP.

\section{Epigenetic effects on other aspects of the maternal state?}

The demands of motherhood are rich, unpredictable and variable. As such, global and compensatory changes in spatial learning, recognition memory, foraging, etc. emerge as a

result of motherhood (Kinsley and Lambert, 2008; Kinsley et al., 1999; Macbeth et al., 2008; Lambert et al., 2005). The extent to which other behavioral changes associated with motherhood (better memory, foraging, etc.) are due to epigenetic changes is an area that deserves investigation. It is clear that estradiol and oxytocin can facilitate learning and memory via the activation of epigenetic mechanisms. An elegant series of experiments has demonstrated that estradiol facilitates memory formation in the hippocampus (Fortress and Frick, 2014). For example, microinjection of estradiol directly into the dorsal hippocampus enhances novel object recognition in female mice (Zhao et al., 2012; Zhao et al., 2010). Estradiol infusion results in phosphorylated ERK within five-minutes, and increased histone acetylation (acH3K14) within 30-minutes. Blockade of ERK phosphorylation inhibits the behavioral and molecular effects of estradiol on memory formation and histone acetylation. Importantly, these early effects seem to initiate a cascade of epigenetic changes including alterations in HDAC gene expression, which functionally mediates memory formation. It is clear that the coordination of events that must occur to translate the nulliparous female into a mother are manifest and complicated, but are being investigated in ways that ensure that the picture of the maternal brain will begin to emerge in more color and detail in the years to come. Section III explores complementary effects in non-human primates, uniting the 
evidence across diverse groups showing parity effects, especially as they relate to stressresponsiveness and behavioral economies.

\section{Maternal Brain-Induced Resiliency Expressed Across Different Species}

As we have seen thus far, parenthood, broadly defined, requires many changes to behavior and, thus, to underlying neurobiology. Studies on parental behavior in a variety of bi-parental species have shown that becoming a parent involves multiple and remarkable behavioral changes, driven by a combination of neuroendocrine and experiential factors (Bridges, 2008). These parenting-induced modifications extend to brain regions that are not typically associated with parental responses but complement and regulate the enhancements to ancillary parental responses such as foraging efficiency and predator avoidance (Lambert, 2012). For example, reproductively experienced female rats exhibited improved spatial memory in the eight-arm radial maze, dry land maze (DLM), and more exploration in the elevated-plus-maze (EPM) in comparison to nulliparous females (Kinsley et al., 1999; Love et al., 2005).

Follow-up work (Lambert et al., 2005) showed that reproductively experienced females had enhanced foraging behavior, likely a transient mechanism to increase the likelihood of pup survival. And it appears to cut across higher levels of the phylogenetic scale: more recently, similar effects were observed in a bi-parental non-human primate species, the owl monkey (Aotus spp.).

Owl monkeys (genus: Aotus) are a species of New World monkey characterized by the extensive involvement of fathers in the care of the infant. These primates are small (body weight, 1 kg) nocturnal, generalist omnivores that consume fruits, leaves, flowers, insects, 
and small vertebrate prey (Fernandez-Duque, 2007; Wolovich et al., 2010). Owl monkeys possess prolonged and likely exclusively monogamous relationships, enforced through a high level of intra-sexual competition (Mock and Fujioka, 1990; Fernandez-Duque, 2007;

Fernandez-Duque et al., 2008). Unfortunately, research on owl monkeys has mostly focused on their high resistance to parasites, less so their paternal behavior. A recent study investigating the arginine vasopressin $\mathrm{V} 1 \mathrm{a}$ receptor gene $(A V P R 1 A)$ revealed that $A$. azarai has a unique genetic structure for AVPR1A, compared to other primates and mammalian species (Babb et al., 2010). This variation may influence the socio-sexual characteristics of these animals. Hence, as an animal model, they provide a rich opportunity to test complex dynamics related to the behavioral and physiological modifications associated with parental care in both sexes.

In a study conducted at the DuMond Conservancy (Bardi et al, 2014), we hypothesized that more adaptive ancillary behavioral and physiological responses would be observed in RE male and female owl monkeys than found in their non- reproductively experienced counterparts. To begin, we examined foraging ability by installing camera-traps in the home cages of 22 animals (5 RE pairs and 6 non- reproductively experienced pairs). The number of attempts and successful captures of insect prey during the night were collected. To assess their cognitive skills and coping flexibility, we introduced a set of novel objects (coin-purse holders) marked with different symbols representing food with variable caloric rewards and determined physiological stress responses via urine samples assayed for cortisol and DHEA.

This work was particularly focused on the relationship between stress and RE, since prior research had suggested that stress hormones may play an integrative role in parentalinduced neurobiological adaptations. Glucocorticoids, for example, are suppressed in 
lactating females due to a blunted HPA axis (Bardi et al., 2004; French et al., 2004), although it has been reported that, in contrast to several other mammalian species, lactating female marmosets maintain full behavioral and HPA responsiveness to stress, at least in the presence of their infants (Saltzman and Abbott, 2011), a difference related to types of stress. Accordingly, of special interest in the current study was the function of both cortisol and DHEA in adaptive parental responses. Both hormones play crucial roles in stress responses and coping mechanisms (Charney, 2004). DHEA, which is released in tandem with cortisol during physical stress (Izawa et al., 2008), has been associated with providing protection against the negative effects of prolonged exposure to glucocorticoids (Morgan et al., 2009); it provides a kind of buffer.

Potentially related to the cognitive modifications observed in maternal animals, other research has shown that DHEA can act centrally to decrease glucocorticoid-induced neuronal death in the hippocampus, and promotes neurogenesis in the dentate gyrus of the hippocampus and in sensory dorsal root ganglion. Furthermore, the ratio between DHEA and cortisol is a reliable index of neuroprotection (Maninger et al, 2009; Pinnock et al., 2009; Ulmann et al., 2009). Higher DHEA to cortisol ratios, therefore, would be advantageous in parental animals presented with the metabolically expensive challenges associated with caring for offspring.

The results, whereas preliminary, suggest that reproductive experience influences ancillary behavioral and physiological parental characteristics in owl monkeys. Of particular interest, we observed that: 1) reproductively experienced parents were more efficient predators than their non- reproductively experienced counterparts (Fig 1); 2) reproductively experienced parents had significantly higher DHEA-to-cortisol ratios following exposure to 
habituation training and the first day of testing (Fig 2); and 3) based on contact duration with the high value stimuli, reproductively experienced owl monkeys exhibited more efficient foraging strategies than the non- reproductively experienced mating pairs during the foraging test by a 4-fold margin (Fig. 3). Taken together, it is apparent that reproductive experience significantly modifies both the male and female parent's behavioral and hormonal repertoire in response to a challenging cognitive paradigm in owl monkeys, extending the parental brain phenomenon to owl monkeys. These data, corroborating previous research demonstrating adaptive modifications in foraging efficiency and emotional responses in RE rodents (Lambert et al., 2013), suggest a general enhancement of ancillary parental responses that aids in the successful care of offspring, ascending the phylogenetic scale from rodents to higher species.

\section{The Genetic Involvement in Maternal Behavior}

A most basic relationship in the mammalian social organization is that of mother and offspring. Most infants would be hard-pressed to survive without the mother, as they are dependent on her for nourishment, protection, warmth, development - in essence, survival. The mother-offspring experience is especially important in primates, where a long postnatal developmental period, high parental investment, and singleton births are the norm (Falk, 2000). Each infant takes up a substantial proportion of the female's lifetime reproductive potential and variation in infant survival is likely a predominant factor in female reproductive success. Hence, this variation would induce high selection pressure on heritable components of maternal behavior regulation (Pryce, 1996; Strathearn, 2011). 
In primates, it has been difficult to assess the influence of genetic variation on complex behavioral phenotypes due to small numbers of subjects in most studies, and the numerous environmental factors that may influence the behavior. Genetic analyses have mainly been inferential. In several primate species, some aspects of maternal style and incidence of infant abuse have been found to be consistent from generation to generation (Berman, 1990; Maestripieri et al., 1997), suggesting a stable genetic (or epigenetic) regulation. As alternative animal models, advances in the use of inbred rodent strains or transgenic mice have provided valuable information concerning the influence of particular genes on physiology and behavior (Bosch and Neumann, 2008; Leckman and Herman, 2002). For example, the neuromedin B receptor ( $N M B-R$ ) pathway is involved in activity, feeding and anxiety-related behaviors. $N M B-R$ deficient mice have a longer latency to recover normal maternal behavior after restraint stress than wild type mice (Yamada et al., 2002). The RR strain of mouse has limited nurturing ability (although the mechanism may be physiological rather than behavioral), and quantitative trait locus (QTL) analysis indicates that a locus influencing this phenotype exists on chromosome 5 (Suto et al., 2002). Mice severely depleted of striatal dopamine (DA) had severe deficits in pup retrieval and licking/grooming behavior (Henschen et al., 2013). Thus, resilience and parental behavior have intriguing links.

Analyses of genetic knock-out models have also resulted in the identification of genes that influence maternal behavior. The FosB gene is related to the display of "nurturing" behavior in mice (Brown et al., 1996; Kuroda et al., 2008). The offspring of homozygous mothers did not survive, and this was not due to lactational failure, reproductive tract abnormalities, hormone status, or sensory or perceptual abnormalities. FosB probably acts in 
the preoptic area of the hypothalamus, already implicated in the control of maternal behavior (Brown et al., 1996). A null mutation of the prolactin receptor gene results in profound deficits in maternal care in primiparous mice (Lucas et al., 1998). Follow-up studies did find that reproductive experience increases central prolactin responsiveness (Anderson et al., 2006). Dopamine beta hydroxylase gene ( $D b h)$ disruption results in impairment of maternal behavior, which can be reversed by prenatal injection of a norepinephrine precursor (Strathearn, 2011; Thomas and Palmiter, 1997).

In order to adapt to their environment (both physical and social), animals have to constantly monitor the outcome of their behavior. Flexible, as opposed to fixed or invariant regulation of behavior, is one all the hallmarks of the primate group. In primates, cost:benefit analyses are often associated with the level of social stress experienced by the animal: do gains outweigh costs? Thus, assessing the relationship between maternal stress and maternal behavior at the genetic level is critically important to the study of the onset and maintenance of maternal behavior. In this regard, the focus of several recent studies on the relationship between maternal stress during the peripartum period and the quality and quantity of maternal care indicated that the activity of the hypothalamic-pituitary-adrenal (HPA) axis may be influenced by the short allele of the serotonin transporter gene promoter (5-HTTLPR; Gotlib et al., 2008). Individuals homozygous for the short arm (s/s) of the 5-HTTLPR polymorphism have increased cortisol reactivity to psychosocial stress, which may increase susceptibility to anxiety during a critical phase of the female's life, giving birth and taking care of offspring (Caspi et al., 2007; Gillespie et al., 2005; Goodyer et al., 2009). These data support the hypothesis that there is an increase in HPA axis activity in s/s carriers compared with those homozygous for the $1 / 1$ form of the 5-HTTLPR gene, and that this polymorphism may 
moderate the association between cortisol level and maternal care (Halligan et al., 2004; Jabbi et al., 2007). Further studies have indicated other genes involved in the regulation of the HPA axis function, such as CRHR1, as promising candidates to investigate gene $X$ environment interactions (Bradley et al., 2008). Despite these promising results and the importance of these types of data, there is still a critical need to further our investigation of the association of physiological variations during pregnancy and different genotypes of the serotonin transporter in primates. As we saw above, and will add to below, there are some telling gene expression relationships that appear to cut across different species. All may contribute to maternal behavior, broadly defined.

\section{Variability in Maternal Care}

Primate mothers are not homogeneous, and differences in maternal behavior influence the survival, development, learning ability and physiology of their infants. Research suggests that profound, and sometimes even subtle, differences in maternal care can have long-term consequences for a variety of somatic, reproductive, and behavioral systems in a wide array of mammals. Maternal-infant separation is an extreme and challenging event for infants. Such studies have shown that both short- and long-term responses occur subsequent to removal from the mother (Gilmer and McKinney, 2003; McEwen, 2003; Rilling et al., 2001). Acute and chronic physiological effects of maternal separation have been reported in both rodent and primate models (Pryce et al., 2002). Variation in the serotonin transporter gene promoter (rh5-HTTLPR) modulates early experiential effects on hormonal responses following stress (Barr et al., 2004). Rhesus monkeys (Macaca mulatta) reared in peer groups could be 
differentiated by the serotonin transporter genotype, indicating a genotype-dependent effect of environmental challenge on serotonin function (Bennett et al., 2002).

Prenatal stress, which exerts effects on the developing nervous substrate, has also received significant attention recently for its actions on phenotypic resiliency responses. Further, in rodents, even short periods of prenatal stress can result in offspring with abnormal behavior and physiological responses to fearful stimuli (Weinstock, 1997), and adults with increased corticosterone and defensive withdrawal behaviors (Ward, Johnson, Salm, \& Birkle, 2000). Stress, therefore, broadly defined, can have significant effects on the way in which the organism transacts with, and recovers from, its environment.

\section{Ancillary Behavioral Modifications Related to Parental Care}

Past research has elucidated the fundamental components of pregnancy and motherhood (Lambert, 2012; Numan and Insel, 2003; Numan and Stolzenberg, 2009; Workman et al., 2012), not only emphasizing the crucial role of the quality of maternal care in infant development (Bardi et al., 2003; Gudsnuk and Champagne, 2012; Kaffman and Meaney, 2007), but also how pregnancy and motherhood can reshape the neural, physiological, and behavioral characteristics of maternal mammals (Bridges, 2008). These parenting-induced modifications also extend to brain regions that are not directly associated with maternal responses, such as amygdala and hippocampus (Love et al., 2005; Pawluski et al., 2010; Rima et al., 2009), but are involved in enhancing the mother's efficiency in ancillary parental responses such as foraging efficiency and predator avoidance. From an evolutionary perspective, these changes are adaptive considering that, in addition to attending to immediate needs of the offspring, enhanced foraging abilities and efficient emotional responses enable 
the maternal animal to meet the increased energy demands associated with raising offspring (Anderson and Rutherford, 2012; Kinsley et al., 2008). That is, a female “made bolder” via her reproductive experiences may be more equipped to leave the safety and comfort of her nest and vulnerable offspring to forage, and thereby effectively confront threats en route. Positive adaptations to her cognition would be predicted to translate into greater economy in foraging and a return to her nest more quickly. Both predictions - decreased anxiety and stress and enhanced cognition - have broad experimental support.

Furthermore, evidence of these maternal-related neurobiological modifications has been confirmed in several species, including humans (Brummelte and Galea, 2010; Brunton and Russell, 2010; Lambert 2012; Macbeth and Luine, 2010; Manson, 2008; Zonana and Gorman, 2005). Previous studies in our laboratory compared animals with no reproductive experience to mothers, and it was consistently found that maternal rats have demonstrated enhanced foraging abilities in a spatial task (Kinsley et al., 1999; Lambert et al., 2005) as well as less behavioral and neural evidence of fear reactivity in an open-field task (Wartella et al., 2003). It is possible, therefore, that reproductive experience-mediated plasticity may be a universal phenomenon: reproduction may require significant modifications to brain and behavior otherwise known as adaptation - in order to accomplish the sine qua non of life, which is survive at all costs.

\section{A Model of Non-Human Primate Maternal Behavior: The Owl Monkey}

Owl monkeys (genus: Aotus) are a species of New World monkey characterized by the extensive involvement of fathers in the care of the infant. These primates are small (body weight, $1 \mathrm{~kg}$ ) nocturnal, generalist omnivores that consume fruits, leaves, flowers, insects, 
and small vertebrate prey (Fernandez-Duque, 2007; Wolovich et al., 2010). Owl monkeys possess prolonged and likely exclusively monogamous relationships, enforced through a high level of intra-sexual competition (Mock and Fujioka, 1990; Fernandez-Duque, 2007;

Fernandez-Duque et al., 2008). Unfortunately, research on owl monkeys has mostly focused on their high resistance to parasites, less so their paternal behavior. A recent study investigating the arginine vasopressin $\mathrm{V} 1 \mathrm{a}$ receptor gene $(A V P R 1 A)$ revealed that $A$. azarai has a unique genetic structure for AVPR1A, compared to other primates and mammalian species (Babb et al., 2010). This variation may influence the socio-sexual characteristics of these animals. Hence, as an animal model, they provide a rich opportunity to test complex dynamics related to the behavioral and physiological modifications associated with parental care in both sexes.

Previous research on reproductively experienced rodents has emphasized their adaptive effects; Bardi and colleagues have recently focused on extending these findings to a biparental, nonhuman primate model, the owl monkeys described above. Specifically, we hypothesized that more adaptive ancillary behavioral and physiological responses would be observed in RE male and female owl monkeys than found in their non- reproductively experienced counterparts. To begin, we examined foraging ability by installing camera-traps in the home cages of 22 animals (5 RE pairs and 6 non- reproductively experienced pairs) housed at the DuMond Conservancy in South Miami (Bardi et al., submitted). The number of attempts and successful captures of insect prey during the night were collected. To assess their cognitive skills and coping flexibility, we introduced a set of novel objects (coin-purse holders) marked with different symbols representing food with variable caloric rewards and determined physiological stress responses via urine samples assayed for cortisol and DHEA. 
This work was particularly focused on the relationship between stress and RE, since prior research had suggested that stress hormones may play an integrative role in parentalinduced neurobiological adaptations. Glucocorticoids, for example, are suppressed in lactating females due to a blunted HPA axis (Bardi et al., 2004; French et al., 2004), although it has been reported that, in contrast to several other mammalian species, lactating female marmosets maintain full behavioral and HPA responsiveness to stress, at least in the presence of their infants (Saltzman and Abbott, 2011), a difference related to types of stress. Accordingly, of special interest in the current study was the function of both cortisol and DHEA in adaptive parental responses. Both hormones play crucial roles in stress responses and coping mechanisms (Charney, 2004). DHEA, which is released in tandem with cortisol during physical stress (Izawa et al., 2008), has been associated with providing protection against the negative effects of prolonged exposure to glucocorticoids (Morgan et al., 2009); it provides a kind of buffer.

Potentially related to the cognitive modifications observed in maternal animals, other research has shown that DHEA can act centrally to decrease glucocorticoid-induced neuronal death in the hippocampus, and promotes neurogenesis in the dentate gyrus of the hippocampus and in sensory dorsal root ganglion. Furthermore, the ratio between DHEA and cortisol is a reliable index of neuroprotection (Maninger et al, 2009; Pinnock et al., 2009; Ulmann et al., 2009). Higher DHEA to cortisol ratios, therefore, would be advantageous in parental animals presented with the metabolically expensive challenges associated with caring for offspring.

The results, whereas preliminary, suggest that reproductive experience influences ancillary behavioral and physiological parental characteristics in owl monkeys. Of particular 
interest, we observed that: 1) reproductively experienced parents were more efficient predators than their non- reproductively experienced counterparts (Fig 1); 2) reproductively experienced parents had significantly higher DHEA-to-cortisol ratios following exposure to habituation training and the first day of testing (Fig 2); and 3) based on contact duration with the high value stimuli, reproductively experienced owl monkeys exhibited more efficient foraging strategies than the non- reproductively experienced mating pairs during the foraging test by a 4-fold margin (Fig. 3). Taken together, it is apparent that reproductive experience significantly modifies both the male and female parent's behavioral and hormonal repertoire in response to a challenging cognitive paradigm in owl monkeys, extending the parental brain phenomenon to owl monkeys. These data suggest a general enhancement of ancillary parental responses that aids in the successful care of offspring, ascending the phylogenetic scale from rodents to higher species.

\section{$\underline{\text { Hypothalamic-Pituitary-Adrenal Ramifications }}$}

Owl monkeys, which display a wide range of interest in infants, are dependent on their individual reaction to novelty (neophobia) coupled with the costs and benefits of spending time with a newborn, in order to successfully raise the offspring to weaning. A significant challenge to understanding the neurobiological dynamics involved in paternal behavior is the close association and interactions among the systems regulating the stress response; the sympathetic-adrenomedullary (SAM) system; hypothalamic-pituitary-adrenal (HPA) axis; and the main system regulating male reproductive life, the hypothalamic-pituitary-gonadal (HPG) axis (Corwin and Pajer, 2008; Meltzer-Brody, 2011, Nater et al., 2011). Whereas parentinfant interactions are generally viewed as positive (generally!), affiliative events which build 
social bonds and group stability, are characterized by stress. Unfortunately, the latter is unavoidable as it represents bodily responses to challenges, unavoidable, recurring, and unpredictable events over the lifespan. As previously described, exposure to stress alters HPA activity. Not surprisingly, altered HPA-axis function is considered to be the "final common pathway” for depressive symptomatology, and it has also been implicated in subsequent changes in the underlying serotonin system. Long-lasting hyperactivity of corticotrophin-releasing hormone $(\mathrm{CRH})$ neurons, resulting in increased stress responsiveness, is commonly seen in depressed individuals (Heim and Nemeroff, 2001; Krishnan and Nestler, 2008). Altered HPA axis and SAM system activity can literally trickle down to the HPG axis and impair its functionality, an association supported by the observation that the risk of infant abuse and neglect is highest when HPG axis activity is abruptly changed, such as during social instability, intense fighting within the group members, and hierarchy turn-over (Bardi et al., 2001a; Hoffman et al., 2011; Massen et al., 2012). The interaction among biological risk factors associated with parental behavior has been difficult to disentangle. Consequently, informative data are necessary to elucidate the molecular mechanisms of variability in parenting strategies. Nevertheless, the evolutionary bottom line appears to be that flexibility in the complex systems that regulate parental behavior best ensures reproductive adaptability and eventual success. As we see in Section IV, some good examples can be found through close examination of a substance that has been a major component of reproduction from time immemorial. 


\section{Higher-Order Requlation of Coqnitive Resilience by an Ancient Neuropeptide}

The construction of the maternal brain requires the actions of a large set of complementary neurochemicals. Oxytocin (OT), part of an ancient family of peptides which includes isotocin in fishes, mesotocin in birds, as well as arginine vasotocin and arginine vasopressin (Yamashita and Kitano, 2013), is emerging as a regulator of multiple events, particularly reproductive ones. In mammals, there are at least two forms of the OT peptide itself, a conserved mammalian form and an alternate form, found in some New World monkeys including owl monkeys, which demonstrates one amino acid substitution (Lee et al., 2011; Zingg, 2002). Oxytocin has been co-opted for many different physiological and behavioral functions. For example, its effects may extend beyond the social actions normally ascribed to it, perhaps through approach-avoidance motivational processes (Harari-Dahan and Bernstein (2014). Further, it appears to play a role in the social transfer of information regarding yawning (Collins \& Eguibar, 2010). And, its activity (viz., grooming behavior) may be regulated, in part, by dopamine release in nucleus accumbens (Drago et al., 1986).

But it is the reproductive effects including many that are integral to reproduction such as labor induction, childbirth, orgasm, and contraction of both male and female reproductive tracts (Carter, 1992), which is our focus here. Oxytocin also plays a key role in induction of maternal behavior (Kendrick, 2000; Keverne and Kendrick, 1992; Pedersen et al., 1982; Pedersen and Prange Jr., 1979), and undergoes epigenetic changes with motherhood (see below). Because it is a conserved reproductive hormone involved in the physiological processes of childbirth and lactation - and before that mate attraction and bonding - the 
initiation of maternal behavior, and learning and memory, it is also a key candidate for a role in cognitive resilience in new mothers.

\section{Oxytocin and Cognitive Resilience}

The role of OT in learning and memory, especially though not limited to social memory, is well established (Chini et al., 2013; Savaskan et al., 2008), and not limited to mammals (Beets et al., 2013). In general, OT facilitates the learning of social cues (Gabor et al., 2012). Oxytocin and OT receptor knockout mice are deficient in social memory (Ferguson et al., 2000; Lee et al., 2008; Winslow and Insel, 2002). Oxytocin injected into the medial amygdala before a social encounter rescues this deficit (Ferguson et al., 2000).

In humans, OT is clearly involved in the processing and memory of social information (Gaustella and MacLeod, 2012), generally with a positive effect on the recognition and retention of socially relevant information. Testing for these effects usually employs intranasally administered OT within a relatively narrow dose range (15-24 IU). There is evidence that OT administered either during encoding of social information (Gaustella et al., 2010; Rimmele et al., 2009) or post-encoding (Bartz et al., 2010; Savaskan et al., 2008), can increase social memory retention.

Information on the role of OT in learning and memory in non-social contexts is more limited, but a recent review (Chini et al., 2013) concluded that tests in animals across a variety of phases (acquisition, consolidation, extinction) primarily showed an impairing effect of OT or no effect at all. A minority of studies did show improvements in memory, mostly when given during the consolidation phase. Given observed non-linear dose effects of OT and other peptides (Bales and Perkeybile, 2012; Bales et al., 2013; Bales et al., 2007; Goldman et al., 
2011; Zhong et al., 2012), it is possible that these differences are due to dosage or other methodological issues. It is arguable, however, that social cognition is particularly relevant to the postpartum mother, just as it is to individuals at other times - remembering which other people (or animals) are dangerous, which are helpful, and navigating complex social environments, etc., may be crucial to survival of the mother and her offspring.

The effects of OT on cognition in patient populations are worth mentioning here. Interest in the use of OT as a therapy in autism (Anagnostou et al., 2014; Green and Hollander, 2010; Tachibana et al., 2013) and schizophrenia (Kuehn, 2011; Macdonald and Feifel, 2012) has been rising. As with the human literature in general, the focus has been on social cognition. Results from patients with autism have been mixed, but a recent metaanalysis concluded that most of these studies had at least one positive finding, usually of medium effect size, of OT on social cognition (Preti et al., 2014). Results from tests with patients with schizophrenia suggest an improvement in social but possibly not general cognition (Gibson et al., 2014; Goldman et al., 2011; Pedersen et al., 2011; Woolley et al., 2014).

\section{Is Oxytocin Involved in Cognitive Resilience in Human Mothers?}

Particularly relevant to maternal resilience is the role of OT in postpartum depression. This relationship displays the complexity typical of OT, which can be dose-, sex-, and context-dependent (Bartz et al., 2011). Oxytocin is generally viewed as an anxiolytic (Altemus et al., 2001; Labuschagne et al., 2010; Missig et al., 2010), although chronic administration can be anxiogenic (Peters et al., 2014). Studies from rodents suggest that centrally released OT reduces postpartum anxiety (Lonstein et al., 2014). The anxiety- and 
depressive-like behavior of OT receptor knockout mice, however, did not differ from control mice (Rich et al., 2014). It is a mixed picture.

Recent studies of OT in human subjects have primarily relied on plasma measures, genetic polymorphisms of unknown functional significance, or intranasal administration as an experimental manipulation. Low OT in the second trimester was associated with depression in a vulnerable population, low-income African-American women (Garfield et al., 2014). In another vulnerable population, mothers who reported high psychosocial stress, high plasma OT appeared to exert a protective effect against depressive symptoms; however, plasma OT was not related to measures of maternal behavior or depressive symptoms as a whole (Zelkowitz et al., 2014). Plasma OT in women during late pregnancy was related to increased theory of mind and lower depressive behavior (MacKinnon et al., 2014). One polymorphism in the OT receptor gene interacted with early adversity to predict levels of postpartum depression in a large sample of at-risk mothers (Jonas et al., 2013). Administration of intranasal OT in a small $(\mathrm{n}=25)$ population of postnatally depressed mothers resulted in reports of sadder mood, but more positive reports of the quality of relationship with their infant (Mah et al., 2013). Another small-scale study reported an increase in maternal protectiveness in depressed mothers given intranasal OT (Mah et al., 2014). Thus, in humans exogenous OT appears to promote maternal responses but not necessarily emotional or cognitive resilience in mothers.

Endogenous OT is up-regulated during late pregnancy, and released in bursts during lactation (Prevost et al., 2014; Russell et al., 2001); these events, however, coincide with many other hormonal changes, making it difficult to isolate the role of OT, and steroid hormones may be more easily and commonly measured (Buckwalter et al., 2001). In humans, 
women performed better on cognitive tasks six or 12 months after delivery, compared to the end of pregnancy or the first three months postpartum (Silber et al., 1990). These events correlate with the duration of time the mothers had elevated OT compared to the non-mother controls. That study, however, did not find a significant relationship between OT levels and the cognitive test results. It should be noted that plasma OT is not necessarily an exact proxy for central OT (Amico et al., 1990). It may be telling as well, that all of the cognitive tasks in the Silber study were non-social tasks.

\section{$\underline{\text { Human Health Practices Regarding OT Affect Both Mother and Offspring }}$}

Oxytocin changes during the process of motherhood in a number of different ways. Pitocin, used for labor induction, augmentation, and for prevention of postpartum hemorrhage, is artificial OT. Its use is widespread and on the rise, reaching nearly $100 \%$ in American hospitals in the case of prevention of postpartum hemorrhage (Kenkel et al., 2014). There has been widespread speculation that pitocin administration may incur a risk factor for autism spectrum disorders (Gialloreti et al., 2014; Kenkel et al., 2014; Rojas Wahl, 2004), although the official position of the American College of Obstetrics and Gynecologists is that there is no connection (The American College of Obstetricians and Gynecologists, 2014). A recent large-scale study (Gregory et al., 2013) did find an increased risk of autism in children whose mothers had undergone induction/augmentation during labor. Despite this interest in long-term effects of OT manipulation on the offspring, the mechanism for any offspring risk factors are unclear, and very little research has been done on effects on maternal behavior (including the choice to breast-feed) or cognition, which could theoretically contribute to long-term effects in offspring. 
Beyond the immediate effects on the mother's uterine contractions and other physiological measures, the effects of pitocin on maternal cognition or even maternal mood are very poorly studied and represent a wide-open area in need of research (Bell et al., 2014). The same is true for Caesarean section, a human birth practice that is known to be associated with difficulties in breast-feeding (Brown and Jordan, 2013; Ladomenou et al., 2007; Tully and Ball, 2013), an OT-dependent behavior. The main area of research into Caesarean sections and cognition has focused on whether women are aware during the procedure (Paech et al., 2008), owing to the need for analgesia for the mother, but alertness in the offspring (Lyons and Akerman, 2005). This has left a large question in the literature remaining to be addressed.

In summary, OT is likely to influence cognitive resilience in mothers in a complex fashion dependent on dosage, context (social vs. non-social), and phase of learning. It is most likely to contribute positively to socially relevant cognitive tasks both during and after encoding, during the consolidation phase for non-social learning, and may be protective against changes in mood and cognition in vulnerable mothers. In particular, human manipulations of OT including labor induction and augmentation, and Caesarian section, are poorly studied in relation to effects on cognitive resilience of the mother. The maternal brain is an agent of change and an organ that is both highly responsive to its environment and capable of new and augmented behavior. 


\section{$\underline{\text { V. Overall Conclusions }}$}

We are finding that the maternal brain, with its inherent plasticity, provides the female with the capacity to respond with an even richer and enhanced behavioral repertoire than she possessed as a nullipara. The mother is altered, likely permanently, by her endocrine, neurobiological and pup-related experiences. That is, a mother is anything but onedimensional; likewise, maternal behavior encompasses many facets beyond direct care of young. For instance, consider the many extant and new behaviors the female must perform once her young are present. Building onto and enhancing existing behavioral repertoires such as nest building, foraging and aggression would be expected to happen. With regard to our original argument regarding positive alterations to resilience, it is clear that as more and varied examinations are made of the maternal transition we see how the mother is different from the nullipara, and in ways that combine logically. That is, we continue to discover that a subtle layering of effects contributes to her enhanced survival. In turn, these effects further accrue to the offspring, contributing strongly to their own survival. Hence, the effects are adaptable at both the parental and offspring levels.

In closing, formerly unfamiliar activities are required of the mother, including behaviors such as retrieving wayward pups, grouping and crouching-over, and licking/physically stimulating the offspring, and protecting them against predators. Complementing such pup-directed effects are those that the mother utilizes to acquire resources. In the latter's case, such behaviors oftentimes require interactions with competitors, themselves motivated to acquire either the same goals or, in the case of predators, the mother herself. Thus, a maternal metaphor may capture what we have discussed above. To the ancient Greeks, Artemis was the goddess of childbirth and the hunt, 
mother, protector and provider. Maternal behavior in the rat and other species may combine the many complementary elements that the early Greeks envisioned, different brain regions shaped by a myriad of neural stimuli. What results is a unique amalgam, an offspringchanged organ driven to ensure that reproductive success, the transfer of one's genes to one's offspring in the hopes of withstanding a hostile world, is made real. 


\section{Acknowledgements}

CHK would like to thank the National Science Foundation (BCS-1126471; BCS-0619544); the Grainger Foundation; and the Howard Hughes Medical Institute (HHMI) for their support. Also, CHK wants to express his gratitude for the continuous support by the University of Richmond for the research and scholarship carried out by its students and faculty. MB would like to thank the DuMond Conservancy and Randolph-Macon College for their summer research support. 


\section{References Cited}

Abraham, I.M., Todman, M.G., Korach, K.S., Herbison, A.E., 2004. Critical in vivo roles for classical estrogen receptors in rapid estrogen actions on intracellular signaling in mouse brain. Endocrinology 145, 3055-3061.

Agrati, D., Fernandez-Guasti, A., Ferreno, M., Ferreira, A., 2011. Coexpression of sexual behavior and maternal aggression: the ambivalence of sexually active mother rats toward male intruders. Behav Neurosci 125, 446-451.

Akbari, E.M., Shams, S., Belay, H.T., Kaiguo, M., Razak, Z., Kent, C.F., Westwood, T., Sokolowski, M.B., Fleming, A.S., 2013. The effects of parity and maternal behavior on gene expression in the medial preoptic area and the medial amygdala in postpartum and virgin female rats: A microarray study. Behav Neurosci. 127, 913-922.

Altemus, M., Redwine, L.S., Leong, Y.M., Frye, C.A., Porges, S.W., Carter, C.S., 2001. Responses to laboratory psychosocial stress in postpartum women. Psychosomatic Medicine 63, 814-821.

Amico, J.A., Challinor, S.M., Cameron, J.L., 1990. Pattern of oxytocin concentration in the plasma and cerebrospinal fluid of lactating rhesus monkeys (Macaca mulatta): Evidence for functionally independent pathways in primates. Journal of Clinical Endocrinology and Metabolism 71, 1531-1535. 
Anagnostou, E., Soorya, L., Brian, J., Dupuis, A., Mankad, D., Smile, S., Jacob, S., 2014.

Intranasal oxytocin in the treatment of autism spectrum disorders: a review of literature and early safety and efficacy data in youth. Brain Research,

http://dx.doi.org/10.1016/j.brainres.2014.01.049.

Anderson GM, Grattan DR, van den Ancker W, Bridges RS. 2006. Reproductive experience increases prolactin responsiveness in the medial preoptic area and arcuate nucleus of female rats. Endocrinology 147, 4688-4694.

Bales, K.L., Perkeybile, A.M., 2012. Developmental experiences and the oxytocin receptor system. Hormones and Behavior 61, 313-319.

Bales, K.L., Perkeybile, A.M., Conley, O.G., Lee, M.H., Guoynes, C.D., Downing, G.M., Yun, C.R., Solomon, M., Jacob, S., Mendoza, S.P., 2013. Chronic intranasal oxytocin causes longterm impairment in partner preference formation in male prairie voles. Biological Psychiatry 74, 180-188.

Bales, K.L., Van Westerhuyzen, J.A., Lewis-Reese, A.D., Grotte, N.D., Lanter, J.A., Carter, C.S., 2007. Oxytocin has dose-dependent developmental effects on pair-bonding and alloparental care in female prairie voles. Hormones and Behavior 52, 274-279. 
Banerjee, S.B., Liu, R.C., 2013. Storing maternal memories: hypothesizing an interaction of experience and estrogen on sensory cortical plasticity to learn infant cues. Front. Neuroendocrinol. 34, 300-314.

Bardi M, Eckles M, Kirk E, Landis T, Evans S, Lambert KG. (2014). Parity modifies endocrine hormones in urine and problem-solving strategies of captive owl monkeys (Aotus spp.). Comp Med. 64, (6):486-95.

Bartz, J.A., Zaki, J., Bolger, N., Ochsner, K.N., 2011. Social effects of oxytocin in humans: context and person matter. Trends in Cognitive Sciences 15, 301-309.

Bartz, J.A., Zaki, J., Ochsner, K.N., Bolger, N., Kolevzon, A., Ludwig, N., Lydon, J.E., 2010. Effects of oxytocin on recollections of maternal care and closeness. Proceedings of the National Academy of Sciences 107, 21371-21375.

Bauer, J.H., 1983. Effects of maternal state on the responsiveness to nest odors of hooded rats. Physiol Behav 30, 229-232.

Beach, R., 1979. Mosquitoes: biting behavior inhibited by ecdysone. Science 205, 829-831.

Beato, M., Klug, J., 2000. Steroid hormone receptors: an update. Hum Reprod Update 6, 225236. 
Beets, I., Temmerman, L., Janssen, T., Schoofs, L., 2013. Ancient neuromodulation by vasopressin/oxytocin-related peptides. Worm 2, e24246.

Bell, A.F., Erickson, E.N., Carter, C.S., 2014. Beyond labor: the role of natural and synthetic oxytocin in the transition to motherhood. J Midwifery Women’s Health, 59, 35-42.

Berman, C.M. (1990). Intergenerational transmission of maternal rejection rates among freeranging rhesus monkeys. Anim. Behav. 39, 329-337.

Berry, B., McMahan, R.; Gallagher, M. 1997. Spatial learning and memory at defined points of the estrous cycle: Effects on performance of a hippocampal-dependent task. Behavioral Neuroscience 111, 267-274.

Bishop, C.V., Stormshak, F., 2008. Non-genomic actions of progesterone and estrogens in regulating reproductive events in domestic animals. Vet. J. 176, 270-280.

Bjornstrom, L., Sjoberg, M., 2005. Mechanisms of estrogen receptor signaling: convergence of genomic and nongenomic actions on target genes. Mol Endocrinol 19, 833-842.

Bodensteiner, K.J., Cain, P., \& Ray, A.S., Hamula L.A. 2006. Effects of pregnancy on spatial cognition in female hooded Long-Evans rats. Hormones and Behavior 49, 303-314. 
Bosch, O.J., Neumann, I.D. 2008. Brain vasopressin is an important regulator of maternal behavior independent of dams' trait anxiety. Proc Natl Acad Sci U S A. 105, 17139-17144.

Bridges, R., Zarrow, M.X., Gandelman, R., Denenberg, V.H., 1972. Differences in maternal responsiveness between lactating and sensitized rats. Dev Psychobiol 5, 123-127.

Bridges, R.S., 1975. Long-term effects of pregnancy and parturition upon maternal responsiveness in the rat. Physiol Behav 14, 245-249.

Bridges, R.S., 1977. Parturition: Its role in the long term retention of maternal behavior in the rat. Physiology and Behavior 18, 487-490.

Bridges, R.S., 1978. Retention of rapid onset of maternal behavior during pregnancy in primiparous rats. Behav Biol 24, 113-117.

Brown, A., Jordan, S., 2013. Impact of birth complications on breastfeeding duration: an internet survey. Journal of Advanced Nursing 69, 828-839.

Brown, J.R., Ye, H., Bronson, R.T., Kikkes, P. and Geenberg, M.E. (1996). A defect in nurturing in mice lacking the immediate early gene fosB. Cell 86, 297-309.

Buckwalter, J.G., Buckwalter, D.K., Bluestein, B.W., Stanczyk, F.Z., 2001. Pregnancy and post partum: changes in cognition and moode, in: Russell, J.A., Douglas, A.J., Windle, R.J., Ingram, 
C.D. (Eds.), The Materrnal Brain: Neurobiological and Neuroendocrine Adaptation and Disorders in Pregnancy and Post Partum. Elsevier, Amsterdam, pp. 303-319.

Bystrova, K., Ivanova, V., Edhborg, M., Matthiesen, A.S., Ransjo-Arvidson, A.B., Mukhamedrakhimov, R., Uvnas-Moberg, K., Widstrom, A.M., 2009. Early contact versus separation: effects on mother-infant interaction one year later. Birth 36, 97-109.

Canavan, S.V., Mayes, L.C., Treloar, H.B., 2011. Changes in maternal gene expression in olfactory circuits in the immediate postpartum period. Front Psychiatry 2, 40.

Carter, C.S., 1992. Oxytocin and sexual behavior. Neurosci.Biobehav.Rev. 16, 131-144.

Champagne, F.A., Weaver, I.C., Diorio, J., Sharma, S., Meaney, M.J., 2003. Natural variations in maternal care are associated with estrogen receptor alpha expression and estrogen sensitivity in the medial preoptic area. Endocrinology 144, 4720-4724.

Chini, B., Leonzino, M., Braida, D., Sala, M., 2013. Learning about oxytocin: pharmacologic and Falk, D., 2000. Primate Diversity. WW Norton and Company.

Collins, G.T. \& Eguibar, J.R. (2010). Neuropharmacology of yawning. Front Neurol Neurosci., 28, 90-106. 
Cortes-Mendoza, J., Diaz de Leon-Guerrero, S., Pedraza-Alva, G., Perez-Martinez, L., 2013. Shaping synaptic plasticity: the role of activity-mediated epigenetic regulation on gene transcription. Int J Dev Neurosci 31, 359-369.

Del Cerro, M.C., Perez Izquierdo, M.A., Rosenblatt, J.S., Johnson, B.M., Pacheco, P., Komisaruk, B.R., 1995. Brain 2-deoxyglucose levels related to maternal behavior-inducing stimuli in the rat. Brain Res 696, 213-220.

Drago, F., Caldwell, J.D., Pedersen, C.A., Continella, G., Scapagnini, U., Prange, A.J. (1986). Dopamine neurotransmission in the nucleus accumbens may be involved in oxytocin-enhanced grooming behavior of the rat. Pharmacol Biochem Behav., 24, 1185-1188.

Duong, V., Licznar, A., Margueron, R., Boulle, N., Busson, M., Lacroix, M., Katzenellenbogen, B.S., Cavailles, V., Lazennec, G., 2006. ERalpha and ERbeta expression and transcriptional activity are differentially regulated by HDAC inhibitors. Oncogene 25, 1799-1806.

Edwards, D.P., 2000. The role of coactivators and corepressors in the biology and mechanism of action of steroid hormone receptors. J Mammary Gland Biol Neoplasia 5, 307-324.

Erlandsson, K., Dsilna, A., Fagerberg, I., Christensson, K., 2007. Skin-to-skin care with the father after cesarean birth and its effect on newborn crying and prefeeding behavior. Birth 34, 105-114. 
Esposito, G., Yoshida, S., Ohnishi, R., Tsuneoka, Y., Rostagno Mdel, C., Yokota, S., Okabe, S., Kamiya, K., Hoshino, M., Shimizu, M., Venuti, P., Kikusui, T., Kato, T., Kuroda, K.O., 2013. Infant calming responses during maternal carrying in humans and mice. Curr Biol. 23, 739-745.

Ferguson, J.N., Young, L.J., Hearn, E.F., Matzuk, M.M., Insel, T.R., Winslow, J.T., 2000. Social amnesia in mice lacking the oxytocin gene. Nature Genetics 25, 284-288.

Fleming, A.S., Cheung, U., Myhal, N., Kessler, Z., 1989. Effects of maternal hormones on 'timidity' and attraction to pup-related odors in female rats. Physiol Behav 46, 449-453.

Fleming, A.S., Corter, C., Franks, P., Surbey, M., Schneider, B., Steiner, M., 1993. Postpartum factors related to mother's attraction to newborn infant odors. Dev Psychobiol 26, 115-132.

Fleming, A.S., Korsmit, M., 1996. Plasticity in the maternal circuit: effects of maternal experience on Fos-Lir in hypothalamic, limbic, and cortical structures in the postpartum rat. Behav Neurosci 110, 567-582.

Fleming, A.S., O'Day, D.H., Kraemer, G.W., 1999. Neurobiology of mother-infant interactions: experience and central nervous system plasticity across development and generations. Neurosci Biobehav Rev 23, 673-685. 
Fleming, A.S., Ruble, D., Krieger, H., Wong, P.Y., 1997. Hormonal and experiential correlates of maternal responsiveness during pregnancy and the puerperium in human mothers. Horm Behav 31, 145-158.

Fleming, A.S., Walsh, C., 1994. Neuropsychology of maternal behavior in the rat: c-fos expression during mother-litter interactions. Psychoneuroendocrinology 19, 429-443.

Foradori, C.D., Weiser, M.J., Handa, R.J., 2008. Non-genomic actions of androgens. Front Neuroendocrinol 29, 169-181.

Fortress, A.M., Frick, K.M., 2014. Epigenetic regulation of estrogen-dependent memory. Front Neuroendocrinol, pii: S0091-3022(14)00048-X. doi: 10.1016/j.yfrne.2014.05.001.

Gabor, C.S., Phan, A., Clipperton-Allen, A.E., Kavaliers, M., Choleris, E., 2012. Interplay of oxytocin, vasopressin, and sex hormones in the regulation of social recognition. Behavioral Neuroscience 126, 97-109.

Gagnidze, K., Weil, Z.M., Faustino, L.C., Schaafsma, S.M., Pfaff, D.W., 2013. Early histone modifications in the ventromedial hypothalamus and preoptic area following oestradiol administration. J Neuroendocrinol 25, 939-955. 
Gammie, S.C., Hasen, N.S., Awad, T.A., Auger, A.P., Jessen, H.M., Panksepp, J.B., Bronikowski, A.M., 2005. Gene array profiling of large hypothalamic CNS regions in lactating and randomly cycling virgin mice. Brain Res Mol Brain Res 139, 201-211.

Gandelman, R., Zarrow, M.X., Denenberg, V.H., 1973. Maternal Behavior: Differences between mother and virgin mice as a function of testing procedure. Developmental Psychobiology 3, 207214.

Garfield, L., Giurgescu, C., Carter, C.S., Holditch-Davis, D., McFarlin, B.L., Schwertz, D., Seng, J.S., White-Traut, R., 2014. Depressive symptoms in the second trimester relate to low oxytocin levels in African-American women: a pilot study. Archives of Women's Mental Health, in press.

Gatewood, J. D. Morgan, M.D., Eaton, M., McNamara, I.M., Stevens, L.F., Macbeth, A.H., Meyer, E.A.A., Lomas, L.M., Kozub, F.J., Lambert, K.G. and Kinsley, C.H. 2005. Motherhood mitigates aging-related decrements in learning and memory. Brain Res. Bul. 66, 91-98.

Gaulin, S. J. 1995. Does evolutionary theory predict sex differences in the brain? In M. S. Gazzaniga (Ed.), The cognitive neurosciences (pp. 1211-1224). Cambridge, MA: MIT Press.

Gaulin, S. J. C., \& Fitzgerald, R. W. 1986. Sex differences in spatial ability: An evolutionary hypothesis and test. The American Naturalist 127, 74-88. 
Gialloreti, L.E., Benvenuto, A., Benassi, F., Curatolo, P., 2014. Are caesarian sections, induced labor, and oxytocin regulation linked to Autism Spectrum Disorders? Medical Hypotheses 82, 713-718.

Gibson, C.M., Penn, D.L., Smedley, K.L., Leserman, J., Elliott, T., Pedersen, C.A., 2014. A pilot six-week randomized controlled trial of oxytocin on social cognition and skills in schizophrenia. Schizophrenia Research 156, 261-265.

Goldman, M.B., Gomes, A.M., Carter, C.S., Lee, R., 2011. Divergent effects of two different doses of intranasal oxytocin on facial affect discrimination in schizophrenic patients with and without polydipsia. Psychopharmacology 216, 101-110.

Graustella, A.J., Einfeld, S.L., Gray, K.M., Rinehart, N.J., Tonge, B.J., Lambert, T.J., Hickie, I.B., 2010. Intranasal oxytocin improves emotion recognition for youth with autism spectrum disorders. Biological Psychiatry 67, 692-694.

Graustella, A.J., MacLeod, C., 2012. A critical review of the influence of oxytocin nasal spray on social cognition in humans: Evidence and future directions. Hormones and Behavior 61, 410418.

Green, J.J., Hollander, E., 2010. Autism and oxytocin: new developments in translational approaches to therapeutics. Neurotherapeutics 7, 250-257. 
Gregory, S.G., Anthopolos, R., Osgood, C.E., Grotegut, C.A., Miranda, M.L., 2013. Association of autism with induced or augmented childbirth in North Carolina birth record (1990-1998) and education research (1997-2007) databases. JAMA Pediatrics 167, 959-966.

Gross, S.M., Resnik, A.K., Nanda, J.P., Cross-Barnet, C., Augustyn, M., Kelly, L., Paige, D.M., 2011. Early postpartum: a critical period in setting the path for breastfeeding success. Breastfeed Med 6, 407-412.

Hackman, D.A., Farah, M.J., Meaney, M.J., 2010. Socioeconomic status and the brain: mechanistic insights from human and animal research. Nat Rev Neurosci 11, 651-659.

Harari-Dahan, O. \& Bernstein, A. (2014). A general approach-avoidance hypothesis of oxytocin: accounting for social and non-social effects of oxytocin. Neurosci Biobehav Rev., 47, 506-519.

Henschen CW, Palmiter RD, Darvas M. 2013. Restoration of dopamine signaling to the dorsal striatum is sufficient for aspects of active maternal behavior in female mice. Endocrinology. 154, 4316-4327.

Jacobs, L.F., Gaulin, S.J.C., Sherry, D.F. \& Hoffman, G.E. (1990). Evolution of spatial cognition: Sex-specific patterns of spatial behavior predict hippocampal size. Proceedings of the National Academy of Sciences 87, 6349-6352. 
Jin, S.H., Blendy, J.A., Thomas, S.A., 2005. Cyclic AMP response element-binding protein is required for normal maternal nurturing behavior. Neuroscience 133, 647-655.

Jonas, W., Mileva-Seitz, V., Girard, A.W., Bisceglia, R., Kennedy, J.L., Sokolowski, M., Meaney, M.J., Fleming, A.S., Steiner, M., Team, M.R., 2013. Genetic variation in oxytocin rs2740210 and early adversity associated with postpartum depression and breastfeeding duration. Genes, Brain, and Behavior 12, 681-694.

Josefsson, A., Theodorsson, E., Berg, G., Sydsjö, G. \& Hilke, S. (2010). Complex biphasic changes of neuropeptide concentrations in the rat limbic system during pregnancy and parturition. The Open Neuroendocrinology Journal, 3, 45-51.

Kalkhoven, E., 2004. CBP and p300: HATs for different occasions. Biochem Pharmacol 68, $1145-1155$.

Kandel, E.R., Schwartz, J.H. \& Jessell, T.M. (1991). Principles of Neural Science. Elsevier.

Kelly, M.J., Levin, E.R., 2001. Rapid actions of plasma membrane estrogen receptors. Trends Endocrinol Metab 12, 152-156.

Kendrick, K.M., 2000. Oxytocin, motherhood and bonding. Experimental Physiology 85, 111S$124 S$. 
Kenkel, W.M., Yee, J.R., Carter, C.S., 2014. Is oxytocin a maternal-fetal signaling molecule at birth? Implications for development. Journal of Neuroendocrinology, in press.

Keverne, E.B., Kendrick, K.M., 1992. Oxytocin Facilitation of Maternal-Behavior in Sheep. Annals of the New York Academy of Sciences 652, 83-101.

Keyser, L., Stafisso-Sandoz, G., Gerecke, K., Jasnow, A., Nightingale, L., Lambert, K.G., Gatewood, J. \& Kinsley, C.H. Alterations of medial preoptic area neurons following pregnancy and pregnancy-like steroidal treatment in the rat. Brain Research Bulletin 55, 737-745, 2001.

Kim, P., Leckman, J.F., Mayes, L.C., Feldman, R., Wang, X., Swain, J.E., 2010. The plasticity of human maternal brain: longitudinal changes in brain anatomy during the early postpartum period. Behav Neurosci 124, 695-700.

Kinsley, C.H., Blair, J.C., Karp, N.E., Hester, N.W., McNamara, I.M., Orthmeyer, A.L., McSweeney, M.C., Bardi, M., Karelina, K., Christon, L.M., Sirkin, M.R., Victoria, L.W., Skurka, D.J., Fyfe, C.R., Hudepohl, M.B., Felicio, L.F., Franssen, R.A., Meyer, E.E.A., da Silva, I.S., and Lambert, K.G. The Mother as Hunter: Significant Reduction in Foraging Costs through Enhancements of Predation in Maternal Rats. Hormones and Behavior, 66, 649-654.

Kinsley, C.H., Bridges, R.S., 1990. Morphine treatment and reproductive condition alter olfactory preferences for pup and adult male odors in female rats. Dev Psychobiol 23, 331-347. 
Kinsley, C.H., Franssen, R.A. \& Meyer, E.A. (2012). Reproductive Experience may Positively Adjust the Trajectory of Senescence. Current Topics in Behavioral Neuroscience, 10, 317-345.

Kinsley, C. H., Trainer, R., Stafisso-Sandoz, G., Quadros, P., Marcus, L.K., Hearon, C., Meyer, E.A., Hester, N., Morgan, M., Kozub, F.J., and Lambert, K.G., 2006. Motherhood and the hormones of pregnancy modify concentrations of hippocampal neural dendritic spines. Horm. Behav. 49, 131-142.

Kinsley, C. H., Madonia, L., Gifford, G. W., Tureski, K., Griffin, G. R., Lowry, C., Williams, J., Collins, J., McLearie, H., \& Lambert, K., 1999. Motherhood improves learning and memory. Nature 402, 137-138.

Kuehn, B.M., 2011. Scientists probe oxytocin therapy for social deficits in autism, schizophrenia. Journal of the American Medical Association, 305, 659-661.

Kuroda, K.O., Meaney, M.J., Uetani, N. and Kato, T., 2008. Neurobehavioral basis of the impaired nurturing in mice lacking the immediate early gene FosB. Brain Res. 1211, 57-71.

Kuroda, K.O., Meaney, M.J., Uetani, N., Fortin, Y., Ponton, A., Kato, T., 2007. ERK-FosB signaling in dorsal mPOA neurons plays a major role in the initiation of parental behavior in mice. Mol Cell Neurosci 36, 121-131. 
Labuschagne, I., Phan, K.L., Wood, A., Angstadt, M., Chua, P., Heinrichs, M., Stout, J.C., Nathan, P.J., 2010. Oxytocin attenuates amygdala reactivity to fear in generalized social anxiety disorder. Neuropsychopharmacology 35, 2403-2413.

Ladomenou, F., Kafatos, A., Galanakis, E., 2007. Risk factors related to intention to breastfeed, early weaning and suboptimal duration of breastfeeding. Acta Paediatrica 96, 1441-1444.

Lambert, K.G., Berry, A.E., Griffin, G., Amory-Meyer, E.A., Madonia-Lomas, L.F., Love, G., Kinsley, C.H., 2005. Pup exposure differentially enhances foraging ability in primiparous and nulliparous rats. Physiology and Behavior 85, 799-806.

Lee, A.G., Cool, D.R., Grunwald, W.C.J., Neal, D.E., Buckmaster, C.L., Cheng, M.Y., Hyde, S.A., Lyons, D.M., Parker, K.J., 2011. A novel form of oxytocin in New World monkeys. Biology Letters 7, 584-587.

Lee, H.J., Caldwell, H.K., Macbeth, A.H., Tolu, S.G., Young III, W.S., 2008. A conditional knockout mouse line of the oxytocin receptor. Endocrinology 149, 3256-3263.

Lonstein, J.S., Maguire, J., Meinlschmidt, G., Neumann, I.D., 2014. Emotion and mood adaptations in the peripartum female: complementary contributions of gamma-aminobutyric acid and oxytocin. Journal of Neuroendocrinology, in press. 
Love, G., Torrey, N., McNamara, I., Morgan, M., Banks, M., Hester, N., Glasper, E., DeVries, C., Kinsley, C., \& Lambert, K. (2005). Maternal experience produces long-lasting behavior modifications in the rat. Behavioral Neuroscience 119, 1084-1096.

Lucas, B.K., Ormandy, C.J., Binart, N., Bridges, R.S. and Kelly, P.A. 1998. Null mutation of the prolactin receptor gene produces a defect in maternal behavior. Endocrinology 139, 4102-4107.

Lyons, G., Akerman, N., 2005. Problems with general anaesthesia for Caesarean section. Minerva Anestesiologica 71, 27-38.

Macdonald, K., Feifel, D., 2012. Oxytocin in schizophrenia: a review of evidence for its therapeutic effects. Acta Neuropsychiatrica 24, 130-146.

MacKinnon, A.L., Gold, I., Feeley, N., Hayton, B., Carter, C.S., Zelkowitz, P., 2014. The role of oxytocin in mothers' theory of mind and interactive behavior during the perinatal period. Psychoneuroendocrinology 48, 52-63.

Maestripieri, D., Wallen, K. and Carroll, K.A. 1997. Infant abuse runs in families of groupliving pigtail macaques. Child Abuse Neglect 21, 465-447.

Mah, B.L., Bakersmans-Kranenburg, M.J., Van Ijzendoorn, M.H., Smith, R., 2014. Oxytocin promotes protective behavior in depressed mothers: a pilot study with the enthusiastic stranger paradigm. Depression and Anxiety, in press. 
Mah, B.L., Van Ijzendoorn, M.H., Smith, R., Bakersmans-Kranenburg, M.J., 2013. Oxytocin in postnatally depressed mothers: its influence on mood and expressed emotion. Progress in NeuroPsychopharmacology and Biological Psychiatry 40, 267-272.

Mann, M., Cortez, V., Vadlamudi, R.K., 2011. Epigenetics of estrogen receptor signaling: role in hormonal cancer progression and therapy. Cancers (Basel) 3, 1691-1707.

McEwen, B.S. \& Woolley, C.S. (1994). Estradiol and progesterone regulate neuronal structure and synaptic connectivity in adult as well as developing brain. Exp. Gerontol. 29, 431-436.

Mehler, K., Wendrich, D., Kissgen, R., Roth, B., Oberthuer, A., Pillekamp, F., Kribs, A., 2011. Mothers seeing their VLBW infants within $3 \mathrm{~h}$ after birth are more likely to establish a secure attachment behavior: evidence of a sensitive period with preterm infants? Journal of Perinatology, 31, 404-410.

Mhyre, A.J., Dorsa, D.M., 2006. Estrogen activates rapid signaling in the brain: role of estrogen receptor alpha and estrogen receptor beta in neurons and glia. Neuroscience 138, 851-858.

Missig, G., Ayers, A.W., Schulkin, J., Rosen, J.B., 2010. Oxytocin reduces background anxiety in a fear-potentiated startle paradigm. Neuropsychopharmacology 35, 2607-2616. 
Nilsson, S., Makela, S., Treuter, E., Tujague, M., Thomsen, J., Andersson, G., Enmark, E., Pettersson, K., Warner, M., Gustafsson, J.A., 2001. Mechanisms of estrogen action. Physiol Rev 81, 1535-1565.

Nishitani, S., Kuwamoto, S., Takahira, A., Miyamura, T., Shinohara, K., 2014. Maternal prefrontal cortex activation by newborn infant odors. Chemical Senses 39, 195-202.

Numan, M., 2006. Hypothalamic neural circuits regulating maternal responsiveness toward infants. Behav Cogn Neurosci Rev 5, 163-190.

Numan, M., Numan, M.J., 1994. Expression of Fos-like immunoreactivity in the preoptic area of maternally behaving virgin and postpartum rats. Behav Neurosci 108, 379-394.

Numan, M., Numan, M.J., 1995. Importance of pup-related sensory inputs and maternal performance for the expression of Fos-like immunoreactivity in the preoptic area and ventral bed nucleus of the stria terminalis of postpartum rats. Behav Neurosci 109, 135-149.

Numan, M., Numan, M.J., Marzella, S.R., Palumbo, A., 1998. Expression of c-fos, fos B, and egr-1 in the medial preoptic area and bed nucleus of the stria terminalis during maternal behavior in rats. Brain Res 792, 348-352.

Numan, M.I., T.R., 2003. The neurobiology of parental behavior. Springer-Verlag, New York. 
Orpen, B.G., Fleming, A.S., 1987. Experience with pups sustains maternal responding in postpartum rats. Physiol Behav 40, 47-54.

Orpen, B.G., Furman, N., Wong, P.Y., Fleming, A.S., 1987. Hormonal influences on the duration of postpartum maternal responsiveness in the rat. Physiology and Behavior, 40, 307315.

Paech, M.J., Scott, K.L., Clavisi, O., Chua, S., McDonnell, N., Group, A.T., 2008. A prospective study of awareness and recall associated with general anaesthesia for caesarian section. International Journal of Obstetric Anesthesia 17, 298-303.

Pawluski JL, Galea LA. Hippocampal morphology is differentially affected by reproductive experience in the mother. J Neurobiol. 2006, 66, 71-81.

Pedersen, C.A., Ascher, J.A., Monroe, Y.L., Prange Jr., A.J., 1982. Oxytocin induces maternal behavior in virgin female rats. Science 216, 648-650.

Pedersen, C.A., Gibson, C.M., Rau, S.W., Salimi, K., Smedley, K.L., Casey, R.L., Leserman, J., Jarskog, L.F., Penn, D.L., 2011. Intranasal oxytocin reduces psychotic symptoms and improves Theory of Mind and social perception in schizophrenia. Schizophrenia Research 132, 50-53. 
Pedersen, C.A., Prange Jr., A.J., 1979. Induction of maternal behavior in virgin rats after intracerebroventricular administration of oxytocin. Proceedings of the National Academy of Sciences 76, 6661-6665.

Peña, C.J., Neugut, D., Champagne, F.A., 2013. Developmental timing of the effects of maternal care on gene expression and epigenetic regulation of hormone receptor levels in female rats. Endocrinology 154, 4340-43451.

Perez-Laso, C., Rubio, S., Martin, J.L., Gomez, F., Segovia, S., Del Cerro, M.C., 2011. Differential regional brain responses to induced maternal behavior in rats measured by cytochrome oxidase immunohistochemistry. Behav Brain Res 223, 293-296.

Peters, S., Slattery, D.A., Uschold-Schmidt, N., Reber, S.O., Neumann, I.D., 2014. Dosedependent effects of chronic central infusion of oxytocin on anxiety, oxytocin receptor binding and stress-related parameters in mice. Psychoneuroendocrinology 42, 225-236.

Preti, A., Melis, M., Siddi, S., Vellante, M., Doneddu, G., Fadda, R., 2014. Oxytocin and autism: a systematic review of randomized controlled trials. Journal of Child and Adolescent Psychopharmacology 24, 54-68.

Prevost, M., Zelkowitz, P., Tulandi, T., Hayton, B., Feeley, N., Carter, C.S., Joseph, L., Pournajafi-Nazarloo, H., Yong Ping, E., Abenhaim, H., Gold, I., 2014. Oxytocin in pregnancy and the postpartum: relations to labor and its management. Frontiers of Public Health, in press. 
Pryce, C.R., 1996. Socialization, hormones, and the regulation of maternal behavior in nonhuman simian primates. Adv. Stud. Behav. 25, 423-473.

Riccio, A., 2010. Dynamic epigenetic regulation in neurons: enzymes, stimuli and signaling pathways. Nat Neurosci 13, 1330-1337.

Rich, M.E., deCardenas, E.J., Lee, H.J., Caldwell, H.K., 2014. Impairments in the initiation of maternal behavior in oxytocin receptor knockout mice. PLoS One 9, e98839.

Rima, B.N., Bardi, M., Friedenberg, J.M., Christon, L., Karelina, K., Lambert, K.G., Kinsley, C.H. 2009. Reproductive experience and the response of female Sprague-Dawley rats to fear and stress. Comparative Medicine, 59, 437-443.

Rimmele, U., Hediger, K., Heinrichs, M., Klaver, P., 2009. Oxytocin makes a face in memory familiar. The Journal of Neuroscience 29, 38-42.

Rojas Wahl, R.U., 2004. Could oxytocin administration during labor contribute to autism and related behavioral disorders? a look at the literature. Medical Hypotheses 63, 456-460.

Russell, J.A., Douglas, A.J., Ingram, C.D., 2001. Brain preparations for maternity-adaptive changes in behavioral and neuroendocrine systems during pregnancy and lactation: an overview. Prog Brain Res., 133-138. 
Savaskan, E., Ehrhardt, R., Schulz, A., Walter, M., Schachinger, H., 2008. Post-learning intranasal oxytocin modulates human memory for facial identity. Psychoneuroendocrinology 33, 368-374.

Scanlan, V.F., Byrnes, E.M., Bridges, R.S., 2006. Reproductive experience and activation of maternal memory. Behav Neurosci 120, 676-686.

Seifritz, E., Esposito, F., Neuhoff, J.G., Luthi, A., Mustovic, H., Dammann, G., von Bardeleben, U., Radue, E.W., Cirillo, S., Tedeschi, G., Di Salle, F., 2003. Differential sex-independent amygdala response to infant crying and laughing in parents versus nonparents. Biol Psychiatry 54, 1367-1375.

Sharma, D., Handa, R.J., Uht, R.M., 2012. The ERbeta ligand 5alpha-androstane, 3beta,17betadiol (3beta-diol) regulates hypothalamic oxytocin (Oxt) gene expression. Endocrinology 153, 2353-2361.

Sheng, M., Greenberg, M.E., 1990. The regulation and function of c-fos and other immediate early genes in the nervous system. Neuron, 4, 477-485.

Silber, M., Almkvist, O., Larsson, B., Uvnas-Moberg, K., 1990. Temporary peripartal impairment in memory and attention and its possible relation to oxytocin concentration. Life Sciences 47, 57-65. 
Stern, J.M., Mackinnon, D.A., 1976. Postpartum, hormonal, and nonhormonal induction of maternal behavior in rats: effects on T-maze retrieval of pups. Horm Behav 7, 305-316.

Stolzenberg, D.S., Numan, M., 2011. Hypothalamic interaction with the mesolimbic DA system in the control of the maternal and sexual behaviors in rats. Neurosci Biobehav Rev 35, 826-847.

Stolzenberg, D.S., Rissman E.F., 2011. Oestrogen-independent, experience-induced maternal behaviour in female mice. Journal of Neuroendocrinology 23, 345-354. .

Stolzenberg, D.S., Stevens, J.S., Rissman, E.F., 2012. Experience-facilitated improvements in pup retrieval; evidence for an epigenetic effect. Horm Behav 62, 128-135.

Stolzenberg, D.S., Stevens, J.S., Rissman, E.F., 2014. Histone deacetylase inhibition induces long-lasting changes in maternal behavior and gene expression in female mice. Endocrinology, in press.

Stolzenberg, D.S., Zhang, K.Y., Luskin, K., Ranker, L., Balkema, J., Bress, J., Numan, M., 2009. A single injection of 17beta-estradiol at the time of pup presentation promotes the onset of maternal behavior in pregnancy-terminated rats. Horm Behav 56, 121-127.

Strathearn L. 2011. Maternal neglect: oxytocin, dopamine and the neurobiology of attachment. J Neuroendocrinol. 23, 1054-1065. 
Suto, J., Yamanaka, H. and Sekikawa, K. (2002). Genetic analysis of inferior nurturing ability in RR mice. Reproduction 123, 53-58.

Tachibana, M., Kagitani-Shimono, K., Mohri, I., Yamamoto, T., Sanefuji, W., Nakimura, A., Oishi, M., Kimura, T., Onaka, T., Ozono, K., Taniike, M., 2013. Long-term administration of intranasal oxytocin is a safe and promising therapy for early adolescent boys with autism spectrum disorders. Journal of Child and Adolescent Psychopharmacology 23, 123-127.

The American College of Obstetricians and Gynecologists, C.o.O.P., 2014. Committee Opinion: Labor induction or augmentation and autism. Obstetrics \& Gynecology 123, 1140-1142.

Thomas, S.A. and Palmiter, R.D. 1997. Impaired maternal behavior in mice lacking norepinephrine and epinephrine. Cell 91, 583-592.

Toran-Allerand, C.D., 2004. Minireview: A plethora of estrogen receptors in the brain: where will it end? Endocrinology 145, 1069-1074.

Tsuneoka, Y., Maruyama, T., Yoshida, S., Nishimori, K., Kato, T., Numan, M., Kuroda, K.O., 2013. Functional, anatomical, and neurochemical differentiation of medial preoptic area subregions in relation to maternal behavior in the mouse. J Comp Neurol 521, 1633-1663. 
Tully, K.P., Ball, H.L., 2013. Maternal accounts of their breast-feeding intent and early challenges after caesarean childbirth. Midwifery 30, 712-719.

Vasudevan, N., Pfaff, D.W., 2007. Membrane-initiated actions of estrogens in neuroendocrinology: emerging principles. Endocr Rev 28, 1-19.

Vasudevan, N., Pfaff, D.W., 2008. Non-genomic actions of estrogens and their interaction with genomic actions in the brain. Front Neuroendocrinol 29, 238-257.

Warren, S. G., Humphreys, A. G.,Juraska,J. M., and Greenough, W. T. 1995. LTP varies across the estrous cycle: Enhanced synaptic plasticity in proestrus rats. Brain Res. 703, 26-30.

Warren SG ${ }^{1}$, Juraska JM. 1997. Spatial and nonspatial learning across the rat estrous cycle. Behav Neurosci. 111, 259-266.

Whitcome, K.K., Shapiro, L.J. \& Lieberman, D.E. 2007. Fetal load and the evolution of lumbar lordosis in bipedal hominins. Nature 450, 1075-1080.

Winslow, J.T., Insel, T.R., 2002. The social deficits of the oxytocin knockout mouse. Neuropeptides 36, 221-229. 
Woolley, J.D., Chuang, B., Lam, O., Lai, W., O'Donovan, A., Rankin, K.P., Mathalon, D.H., Vinogradov, S., 2014. Oxytocin administration enhances controlled social cognition in patients with schizophrenia. Psychoneuroendocrinology 47, 116-125.

Woolley CS ${ }^{1}$, Gould E, Frankfurt M, McEwen BS. Naturally occurring fluctuation in dendritic spine density on adult hippocampal pyramidal neurons. J Neurosci. 1990, 10, 4035-4039.

Woolley, C.S., Gould, E, Frankfurt, M. \& McEwen, B.S. 1990. Long-term and short-term electrophysiological effects of estrogen on the synaptic properties of hippocampal CA1 pyramidal neurons. J. Neurosci. 10, 4035-3225.

Woolley, C.S. \& McEwen, B.S. 1992. Estradiol mediates fluctuation in hippocampal synapse density during the estrous cycle in the adult. J. Neurosci. 12, 2549-2554.

Woolley, C.S. \& McEwen, B.S. 1993. Roles of estradiol and progesterone in regulation of hippocampal dendritic spine density during the estrous cycle in the rat. J. Comp. Neurol. 336, 293-306.

Wu, Z., Autry, A.E., Bergan, J.F., Watabe-Uchida, M., Dulac, C.G., 2014. Galanin neurons in the medial preoptic area govern parental behaviour. Nature 509, 325-330.

Yamada, K., Santo-Yamada, Y. and Wada, K. 2002. Restraint stress impaired maternal behavior in female mice lacking the neuromedin B receptor (NMB-R) gene. Neurosci. Lett. 330, 163-166 
Yamashita, K., Kitano, T., 2013. Molecular evolution of the oxytocin-oxytocin receptor system in eutherians. Molecular and Phylogenetic Evolution 67, 520-528.

Zelkowitz, P., Gold, I., Feeley, N., Hayton, B., Carter, C.S., Tulandi, T., Abenhaim, H.A., Levin, P., 2014. Psychosocial stress moderates the relationships between oxytocin, perinatal depression, and maternal behavior. Hormones and Behavior 66, 351-360.

Zhao, Z., Fan, L., Fortress, A.M., Boulware, M.I., Frick, K.M., 2012. Hippocampal histone acetylation regulates object recognition and the estradiol-induced enhancement of object recognition. J Neurosci 32, 2344-2351.

Zhao, Z., Fan, L., Frick, K.M., 2010. Epigenetic alterations regulate estradiol-induced enhancement of memory consolidation. Proc Natl Acad Sci U S A 107, 5605-5610.

Zhong, S., Monakhov, M., Mok, H.P., Tong, T., Lai, P.S., Chew, S.H., Ebstein, R.P., 2012. Ushaped relation between plasma oxytocin levels and behavior in the trust game. PLoS One. 2012;7(12):e51095. doi: 10.1371/journal.pone.0051095.

Zingg, H.H., 2002. Oxytocin. In: Pfaff, D., Arnold, A.P., Etgen, A.M., Fahrbach, S.E., Rubin, R.T. (Eds.), Hormones, brain, and behavior. Academic Press, New York, 779-802. 


\section{Figure Legends}

Figure 1:

Number of insect prey consumed per hour of observation in reproductively-experienced (RE) owl monkeys versus non-reproductively-experienced (Non-RE) individuals. RE pairs had raised at least two litters prior to data collection. Non-RE pairs raised no offspring. RE owl monkeys were almost three times more proficient in catching insect prey compared to Non-RE monkeys, $\left(\mathrm{F}_{1,18}=16.7, \mathrm{p}<0.01, \mathrm{n}=22\right)$.

Figure 2:

An animal foraging at the coin holders. Black rubber squeeze coin holders were used to hide the marshmallow reward during the three experimental phases. Coin holders showed three different patterns: (1) No Value (NV): the coin holder did not contain a marshmallow and it was marked with a white tape rectangle; (2) Low Value (LV): the coin holder contained a quarter of a small marshmallow hidden in the bottom portion, and it was marked with three horizontal white tape strips; (3) High Value (HV): the coin holder contained two quarter pieces of marshmallow hidden in the bottom part, and was marked with three vertical white tape strips. In this task, RE females spent more time (nearly 4x more) investigating the high value coin holders, compared to Non-RE females, $\left(\mathrm{F}_{1,18}=6.96, \mathrm{p}=0.016, \mathrm{n}=22\right)$. 
Figure 3:

Dehydroepiandrosterone (DHEA) excreted in urine samples following the above cognitive task increased significantly only in RE owl monkeys, compared to Non-RE, $\left(\mathrm{F}_{1,18}=26.3, \mathrm{p}<0.01, \mathrm{n}=22\right)$. That DHEA is associated with neuroprotection suggests that RE may steel animals against the stress of future challenges, thereby contributing to greater efficiency in the behavioral tasks examined above. 


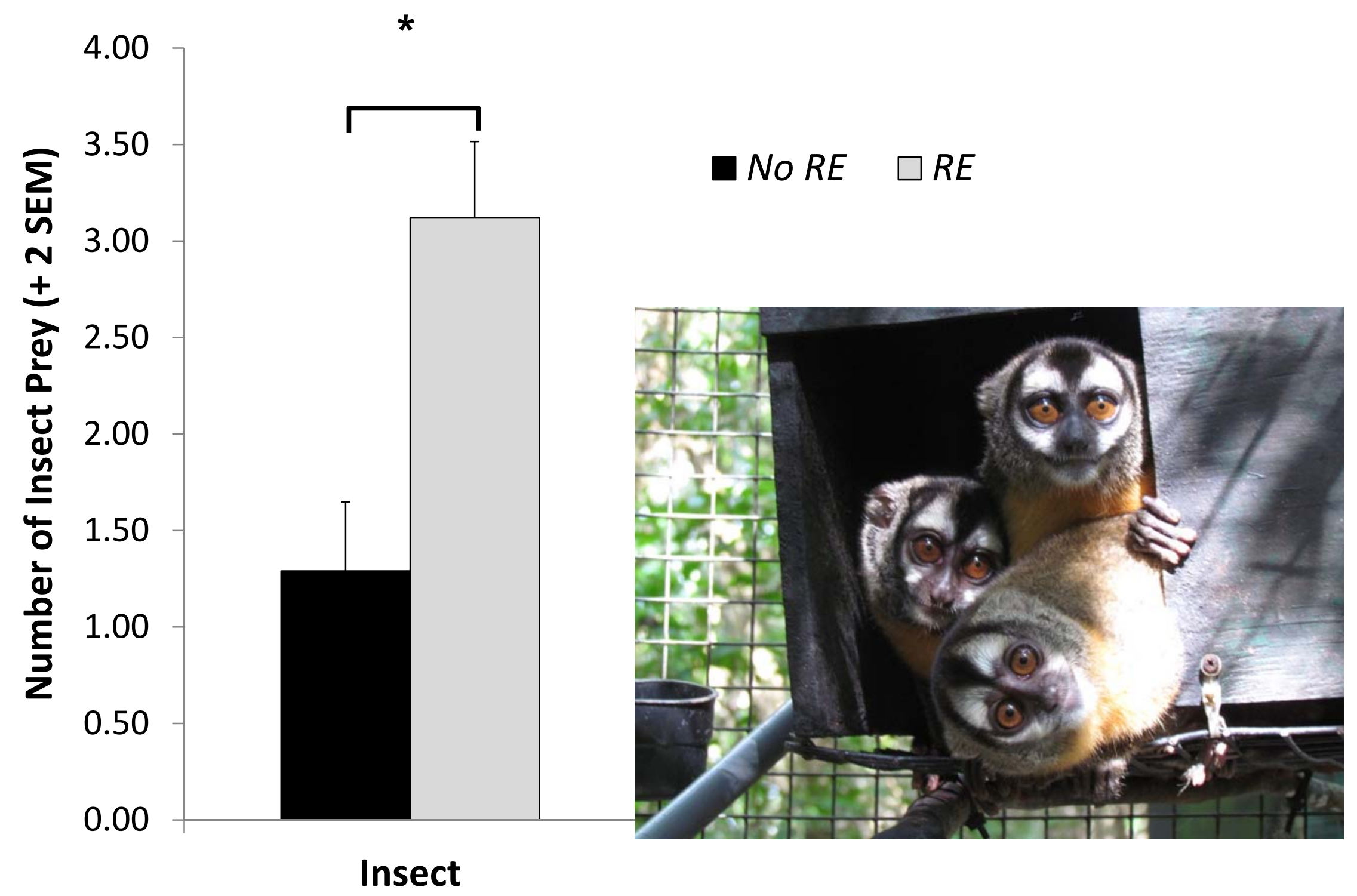

Figure 1 

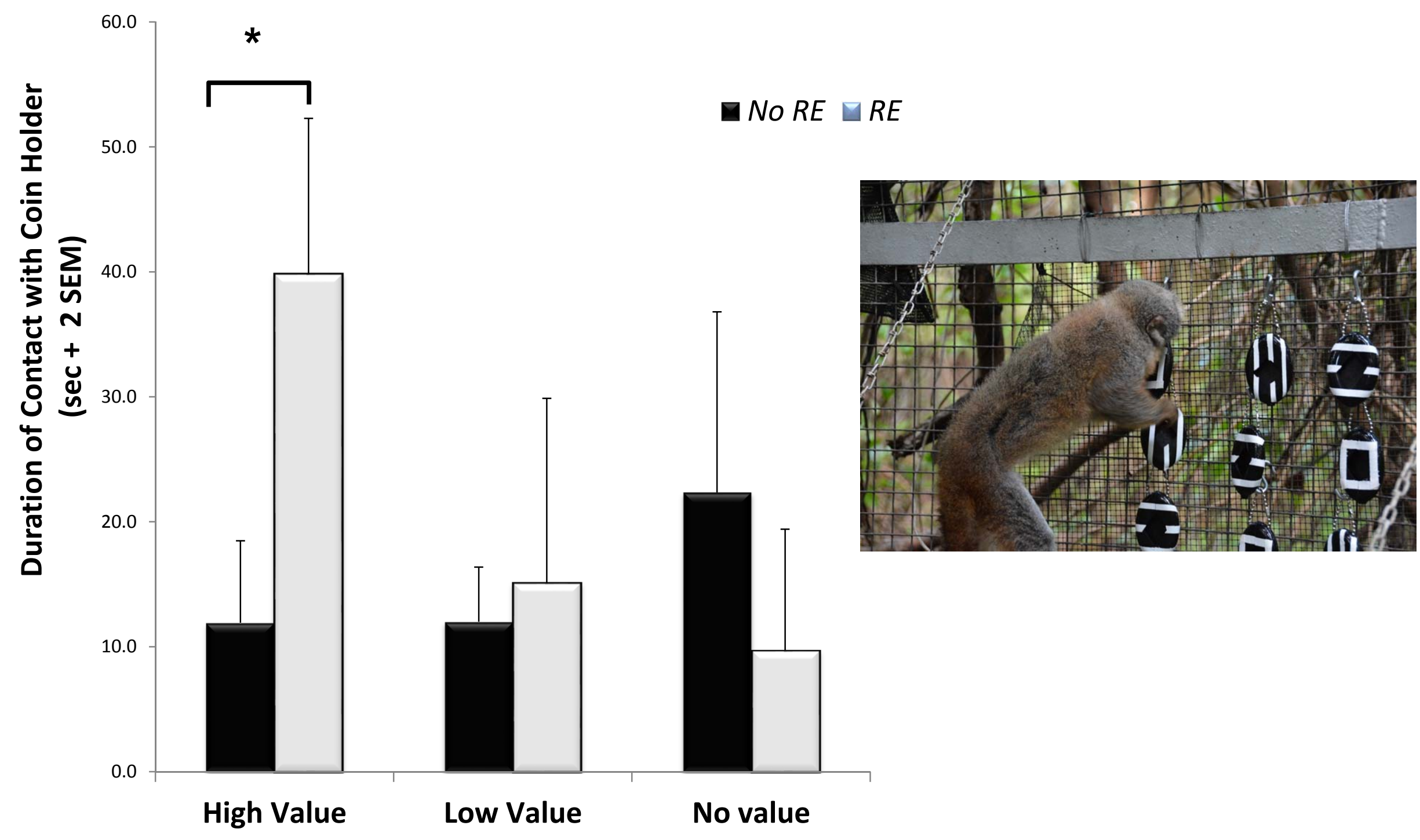

Figure 2 


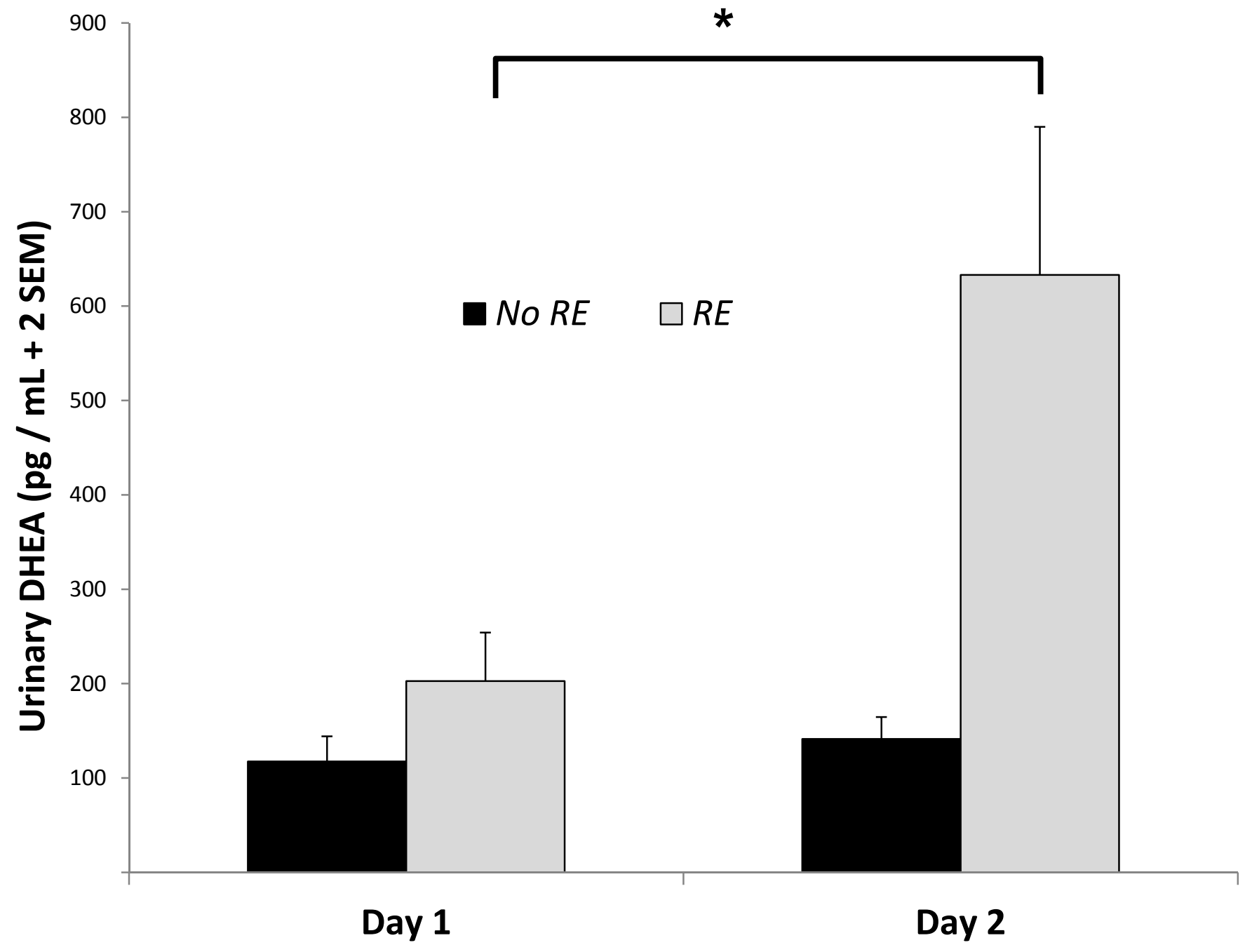

Figure 3 